\title{
NanoSIMS results from olivine-hosted melt embayments: Magma ascent rate during explosive basaltic eruptions
}

\author{
Alexander S. Lloyd ${ }^{\mathrm{a}, *}$, Philipp Ruprechtt ${ }^{\mathrm{a}, 1}$, Erik H. Hauri ${ }^{\mathrm{b}, 2}$, William Rose ${ }^{\mathrm{c}, 3}$, \\ Helge M. Gonnermann ${ }^{\mathrm{d}, 4}$, Terry Plank ${ }^{\mathrm{a}, 5}$ \\ a Lamont Doherty Earth Observatory, Columbia Univ., NY, USA \\ b Carnegie Instit. of Washington, DC, USA \\ c Michigan Tech Univ., Houghton, MI, USA \\ d Rice Univ., Houston, TX, USA
}

\section{A R T I C L E I N F O}

\section{Article history:}

Received 18 December 2013

Accepted 13 June 2014

Available online 21 June 2014

\section{Keywords:}

Magma ascent

Diffusion

Melt inclusions

Volatiles

Explosive eruptions

Basalt

\begin{abstract}
A B S T R A C T
The explosivity of volcanic eruptions is governed in part by the rate at which magma ascends and degasses. Because the time scales of eruptive processes can be exceptionally fast relative to standard geochronometers, magma ascent rate remains difficult to quantify. Here we use as a chronometer concentration gradients of volatile species along open melt embayments within olivine crystals. Continuous degassing of the external melt during magma ascent results in diffusion of volatile species from embayment interiors to the bubble located at their outlets. The novel aspect of this study is the measurement of concentration gradients in five volatile elements $\left(\mathrm{CO}_{2}, \mathrm{H}_{2} \mathrm{O}, \mathrm{S}\right.$, $\mathrm{Cl}, \mathrm{F})$ at fine-scale $(5-10 \mu \mathrm{m})$ using the NanoSIMS. The wide range in diffusivity and solubility of these different volatiles provides multiple constraints on ascent timescales over a range of depths. We focus on four 100-200 $\mu \mathrm{m}$, olivine-hosted embayments erupted on October 17, 1974 during the sub-Plinian eruption of Volcán de Fuego. $\mathrm{H}_{2} \mathrm{O}, \mathrm{CO}_{2}$, and $\mathrm{S}$ all decrease toward the embayment outlet bubble, while $\mathrm{F}$ and $\mathrm{Cl}$ increase or remain roughly constant. Compared to an extensive melt inclusion suite from the same day of the eruption, the embayments have lost both $\mathrm{H}_{2} \mathrm{O}$ and $\mathrm{CO}_{2}$ throughout the entire length of the embayment. We fit the profiles with a 1-D numerical diffusion model that allows varying diffusivities and external melt concentrations as a function of pressure. Assuming a constant decompression rate from the magma storage region at approximately $220 \mathrm{MPa}$ to the surface, $\mathrm{H}_{2} \mathrm{O}, \mathrm{CO}_{2}$ and $\mathrm{S}$ profiles for all embayments can be fit with a relatively narrow range in decompression rates of $0.3-0.5 \mathrm{MPa} / \mathrm{s}$, equivalent to $11-17 \mathrm{~m} / \mathrm{s}$ ascent velocity and an 8 to 12 minute duration of magma ascent from $\sim 10 \mathrm{~km}$ depth. A two stage decompression model takes advantage of the different depth ranges over which $\mathrm{CO}_{2}$ and $\mathrm{H}_{2} \mathrm{O}$ degas, and produces good fits given an initial stage of slow decompression (0.05$0.3 \mathrm{MPa} / \mathrm{s}$ ) at high pressure (>145 MPa), with similar decompression rates to the single-stage model for the shallower stage. The magma ascent rates reported here are among the first for explosive basaltic eruptions and demonstrate the potential of the embayment method for quantifying magmatic timescales associated with eruptions of different vigor.
\end{abstract}

(c) 2014 Elsevier B.V. All rights reserved.

\section{Introduction}

A critical parameter governing the style and intensity of volcanic eruptions is the rate at which magma ascends from the storage region

\footnotetext{
* Corresponding author at: Lamont Doherty Earth Observatory, 127 Comer, 61 Route 9W PO Box 1000, Palisades, NY, 10964-8000, USA. Tel.: +1 845365 8926; fax: +1 8453658155. E-mail addresses: alloyd@ldeo.columbia.edu (A.S. Lloyd), ruprecht@ldeo.columbia.edu (P. Ruprecht), hauri@ciw.edu (E.H. Hauri), raman@mtu.edu (W. Rose), helge@rice.edu (H.M. Gonnermann), tplank@ldeo.columbia.edu (T. Plank).

1 Tel.: + 18453658635 .

2 Tel.: +1202478 8471 .

${ }^{3}$ Tel.: + 19064872367 .

4 Tel.: +17133486263

5 Tel.: +18453658410
}

to the surface. The decompression of ascending magma drives the exsolution of dissolved volatile components from the melt into a separate vapor phase, which increases the buoyancy of the magma and creates a driving force for further ascent and eruption. The interaction of the rate of ascent with the kinetics of bubble nucleation, growth, and coalescence is also an important factor controlling the development of permeability in magmas and therefore how magmas degas and ultimately erupt (Gonnermann \& Manga, 2007; Cashman and Sparks, 2013). Although several factors and feedbacks may affect the style in which magmas erupt, magma ascent rate is fundamental to the dynamics of eruption. However, it is a parameter that has proved difficult to determine, with current estimates limited to a few well-documented eruptions (Rutherford, 2008). 
Many approaches have been employed to quantify magma ascent rates, including but not limited to: fluid dynamical simulations, seismicity, decompression crystallization and bubble nucleation experiments, crystal reaction kinetics, elemental diffusion during ascent, or a combination of these techniques (e.g. Spera, 1984; Endo et al., 1996; Geschwind and Rutherford, 1995; Rutherford and Devine, 2003; Proussevitch and Sahagian, 2005; Szramek et al., 2006; Toramaru, 2006; Castro and Dingwell, 2009; Ruprecht and Plank, 2013). These approaches have revealed magma ascent rates that vary over orders of magnitude $(0.1-30 \mathrm{~m} / \mathrm{s})$ for volcanism with a diversity of magma composition and viscosity, eruption explosivity, and depth resolution from source to vent (i.e. some techniques are sensitive in the shallow crust, while others may provide deeper constraints). Here, we pursue an approach, in which we make use of the preservation of chemical zonation in crystals or glass, and then apply time-dependent diffusion models to obtain the duration of magma ascent (e.g., Demouchy et al., 2006; Peslier and Luhr, 2006; Liu et al., 2007; Ruprecht and Plank, 2013). Our study focuses on hydrous mafic arc volcanism, for which few previous estimates of ascent rate exist.

A petrologic approach that holds much promise for constraining ascent timescales involves the analysis of chemical zonation of volatile species in melt embayments that are found within phenocryst phases (Anderson, 1991; Liu et al., 2007; Humphreys et al., 2008). Essentially melt inclusions (MIs) that have failed to become fully enclosed, melt embayments have also been termed hourglass inclusions, melt pockets, melt tubes, and re-entrants. With the exception of hourglass inclusions that are connected to the exterior melt via a very narrow neck of glass (Anderson, 1991), all of these other features refer to some crystal growth defect that fills with melt and remains connected to the external melt through a wide outlet on the crystal face. While most fully-enclosed melt inclusions preserve magma compositions prior to degassing (Metrich and Wallace, 2008), embayments inevitably experience diffusive volatile loss due to the direct connection to the host melt during ascent and degassing. In some cases this volatile loss is only partial and compositional gradients within the embayment may constrain the timescales of diffusive re-equilibration, which can be related to the decompression rate.

The key assumptions in this approach are that the chemical species of interest within the embayment attempt to remain in equilibrium with an external melt undergoing equilibrium degassing and that the resultant diffusion profile can be spatially resolved to extract meaningful time scales. As near-surface magma ascent is rapid for explosive eruptions, only fast-diffusing volatiles, such as $\mathrm{H}_{2} \mathrm{O}, \mathrm{CO}_{2}$ and $\mathrm{S}$, capture the ascent process. In a pioneering study, Liu et al. (2007) measured $\mathrm{H}_{2} \mathrm{O}$ and $\mathrm{CO}_{2}$ by FTIR in quartz-hosted embayments. However, the large FTIR beam size limited the analysis to two to three spots, and such coarse spatial resolution compromises the temporal resolution. Humphreys et al. (2008) later utilized the embayment technique with plagioclase-hosted embayments, correlating $\mathrm{H}_{2} \mathrm{O}$ concentration with gray scale values measured by electron back-scatter (EBS) for a highly spatially resolved profile. Although they achieved better spatial resolution especially in the critical region near the outlet, the EBS method is unable to quantify the additional constraint on ascent and pressure provided by $\mathrm{CO}_{2}$.

Here we attempt to improve upon prior work by utilizing the unique analytical capabilities of the NanoSIMS (Hauri et al., 2011), which allows for a spatial resolution $(<0.1$ to $10 \mu \mathrm{m}$ raster size) approaching that of the EBS technique, while enabling the analysis of multiple volatile species $\left(\mathrm{H}_{2} \mathrm{O}, \mathrm{CO}_{2}, \mathrm{~S}, \mathrm{Cl}, \mathrm{F}\right)$. We focus on the well-documented October 1974 eruption of Volcán de Fuego (Rose et al., 1978), which was meticulously sampled and includes a comprehensive melt inclusion record (Roggensack, 2001; Berlo et al., 2012; Lloyd et al., 2013). In this study, we model the diffusion of multiple volatile species within melt embayments in olivine to determine magma decompression rate and its relationship to volcanic explosivity.

\section{Background}

This study utilizes the same airfall samples of the Volcán de Fuego October 1974 eruption as in our previous study on melt inclusions (MIs) and the timescales of volatile loss (Lloyd et al., 2013). Four subPlinian eruptions (VEI 4) occurred between October 14 and October 23,1974 , producing $\sim 0.1 \mathrm{~km}^{3}$ of porphyritic, $\mathrm{H}_{2} \mathrm{O}$-rich, high-aluminum basalt (Rose et al., 2008). A comprehensive sample suite was collected by $\mathrm{S}$. Bonis during each eruptive phase. Here we focus on samples erupted on October 17, 1974, to ensure that the analyzed embayments underwent similar ascent, eruptive, and depositional histories, and not the shifts in eruptive behavior often observed during multi-day eruptions (e.g. 2010 Eyjafjallajokull, Gudmundsson et al., 2012). The October 17 phase of the eruption was the most explosive of the 4 main phases and produced about $40 \%$ of the total erupted material (Rose et al., 1978). Furthermore, this phase exhibited a sustained eruptive sequence that does not include the complexities associated with the initiation or cessation of the eruption (Carr and Walker, 1987).

The October 17 phase has been described as a sub-Plinian eruption with major ash flows and extensive airfall from an eruption column that reached stratospheric heights ( $15 \mathrm{~km}$, Rose et al., 1978). Intense explosions with a one-minute periodicity were observed near the vent. The pulsating explosions and bimodal grain size distribution of the tephra suggest that a comminution or milling process could be occurring post-fragmentation in the upper conduit and vent during the eruption (Rose et al., 2008). After the 1974 eruption, the main surface vent of Fuego was observed to be greater than $20 \mathrm{~m}$ in radius and was hypothesized to be connected to the source region by a vertical conduit (Rose et al., 1978).

The extensive prior work on MIs from the October 17 phase of the eruption provides a useful starting point for understanding the preeruptive conditions and decompression path during magma ascent. Shifts in bulk ash geochemistry (Rose et al., 1978), changes in the size and modal proportions of phenocrysts (Roggensack, 2001), and MI heterogeneity (Berlo et al., 2012) have all been presented as evidence for the hybridization of distinct magmas during this 10-day long eruption. It has been speculated that the 1974 eruption either tapped a vertically stratified magma chamber (Rose et al., 1978), or that magma ascent was preceded by mixing of magmas, which fractionated at different depths (Roggensack, 2001; Berlo et al., 2012).

Our work on Fuego MIs erupted on October 17 indicates that a simpler magma system was associated with this phase of the eruption. The linear variation in $\mathrm{K}_{2} \mathrm{O}-\mathrm{SiO}_{2}$, as well as consistent trace-element ratios, reflect degassing-induced crystallization of a single parental magma (Lloyd et al., 2013). This could reflect a fresh influx of basaltic melt preceding the explosive October 17 eruption, whereas the other, less explosive eruptions may have included residual magma that stalled within the plumbing system (Berlo et al., 2012). In Lloyd et al. (2013), we analyzed MIs from multiple pyroclasts of different sizes (ash, lapilli, and volcanic bombs) and discovered systematically lower ( 1 wt.\%) $\mathrm{H}_{2} \mathrm{O}$ concentrations in MIs from both the core and the rim of two $6 \mathrm{~cm}$ bombs, compared to those in ash and lapilli samples. We interpreted this to reflect diffusive $\mathrm{H}_{2} \mathrm{O}$-loss through the olivine host during posteruptive cooling, on a timescale of approximately $10 \mathrm{~min}$. However, because $\mathrm{H}_{2} \mathrm{O}$-loss from ash and lapilli hosted MIs could not be accounted for by post-eruption cooling alone, we considered the possibility that some $\mathrm{H}_{2} \mathrm{O}$-loss also occurred during ascent, and estimated magma ascent rates on the order of $10 \mathrm{~m} / \mathrm{s}$. Once the MIs were corrected for post-entrapment diffusive re-equilibration, the volatile concentrations conformed to a closed-system degassing path, indicating that the MIs were trapped at various depths prior to and during ascent. Here, we use this closed-system degassing path and the associated range of MI entrapment pressures to define initial and external boundary conditions for embayment formation and ascent. By exploiting the differences in solubility and diffusivity of five volatile species, this embayment study provides independent constraints on 
ascent rates that can be compared to the previous estimate derived from olivine-hosted MIs.

\section{Methods}

\subsection{Sample preparation}

During sample preparation, special care was taken to consider the size of each pyroclast and the effect on post-eruptive cooling. Samples were divided into three sizes: volcanic ash (particles with a diameter $<2 \mathrm{~mm}$ ); lapilli (diameter between $2 \mathrm{~mm}$ and $64 \mathrm{~mm}$ ); and volcanic bombs (clasts with a diameter $>64 \mathrm{~mm}$ ). The ash sample (VF-132 IGSN: ASL000001) was sieved without crushing, and loose olivine grains were selected from $250-500 \mu \mathrm{m}$ and from $500-1000 \mu \mathrm{m}$ size fractions. The lapilli sample (VF-129 - IGSN: ASL000002) was collected as a mix of ash and lapilli ranging in size from $30 \mathrm{~mm}$ to less than $0.1 \mathrm{~mm}$. Only pyroclasts greater than $20 \mathrm{~mm}$ in diameter were selected; and of this set, the five largest lapilli were chosen. The bomb sample (VF-137B - IGSN: ASL000003) was selected from a diverse collection for its uniform spherical shape and relatively large size $(60-\mathrm{mm}$ diameter). The bomb was cut so that the material sampled for olivinehosted embayments was derived from the inner $20 \times 20 \times 20 \mathrm{~mm}^{3}$ of the bomb. The vesiculation in these pyroclasts was relatively uniform between clast types and ranged from $40 \%$ to $55 \%$ (estimated by bubble size distribution techniques, Gray A.L., pers comm, 2012); groundmass color was observed to be consistent among all the samples.

After crushing, olivine phenocrysts and fragments ( $10 \%$ by volume) were separated by hand from groundmass ( 60\%), plagioclase $(\sim 25 \%)$, opaque minerals (3\%), and clinopyroxene $(\sim 2 \%)$. Phenocrysts were then picked for optimal melt embayments within the olivine. Although MIs with ideal characteristics are relatively common in these samples, embayments are extremely rare and special care is needed during preparation. In order to approximate one-dimensional diffusion, we selected glassy embayments with a simple tubular shape that were free of secondary inclusions. We chose embayments with evidence of a single bubble at the outlet, ensuring a path to vapor and communication with the conditions in the exterior melt during decompression. Phenocrysts were mounted individually in dental resin and polished on one side parallel to the long axis of the embayment to expose the maximum cross-sectional area for analysis. Once the embayments were exposed, the phenocrysts were removed from the resin and mounted together in indium metal for NanoSIMS (Secondary Ion Mass Spectrometer) and EMP (Electron Micro Probe) analysis. Analysis of the embayments by NanoSIMS was completed first, in order to avoid potential $\mathrm{H}_{2} \mathrm{O}$-loss during exposure to the electron beam and the possibility of $\mathrm{CO}_{2}$ contamination by the EMP carbon coat. Back-scattered electron images were taken for each inclusion after the NanoSIMS analysis.

\subsection{Ion microprobe analysis}

Volatiles $\left(\mathrm{H}_{2} \mathrm{O}, \mathrm{CO}_{2}, \mathrm{Cl}, \mathrm{F}\right.$, and $\left.\mathrm{S}\right)$ in the embayments were measured in one session on a Cameca NanoSIMS 50L at the Carnegie Institute of Washington (CIW), Department of Terrestrial Magnetism. The procedures followed those in Hauri et al. (2011); each location was pre-sputtered for $60 \mathrm{~s}$ using a $10 \mu \mathrm{m} \times 10 \mu \mathrm{m}$ raster to remove surface contaminants. After the presputter, the raster size was reduced to $7.5 \mu \mathrm{m} \times 7.5 \mu \mathrm{m}$, with electronic gating (beam blanking) used to discard data from the crater edge, such that the reported data represent an area within the sputter crater measuring $2.5 \mu \mathrm{m} \times 2.5 \mu \mathrm{m}$. Six replicate analyses of a basaltic glass secondary standard (GL07 D30-1, Hauri et al., 2006) yielded 2 relative standard deviations (standard deviation/average; RSDs) of $4.8 \%$ for ${ }^{12} \mathrm{C}, 5.8 \%$ for ${ }^{16} \mathrm{O}^{1} \mathrm{H}, 6.6 \%$ for $\mathrm{S}$, $8.0 \%$ for $\mathrm{F}$, and $7.6 \%$ for $\mathrm{Cl}$ (see Supplementary Table 1 for calibration standards).

\subsection{Electron microprobe analyses}

Embayments and olivine phenocrysts were analyzed for major elements using a Cameca SX100 microprobe (EMP) at the American Museum of Natural History (AMNH). The analyses of the embayments were performed parallel to the direction of NanoSIMS analysis (Fig. 1). The host olivine phenocryst was then analyzed within $20 \mu \mathrm{m}$ from the inner border with the embayment. Major elements in hydrous glasses and olivine phenocrysts were analyzed using a $10 \mathrm{nA}$ beam current (4-nA for Na; 40-nA for $\mathrm{Cl}$ and S) and a $15 \mathrm{kV}$ accelerating potential with a $5 \mu \mathrm{m}$ diameter beam. Count times on peak for major elements varied between 20s ( $\mathrm{Na}, \mathrm{Mg}, \mathrm{Si}, \mathrm{K}$ ), 30s (Ca, Mn, Al, Fe), 40s (Ti and P), $60 \mathrm{~s}(\mathrm{Cl})$, and $80 \mathrm{~s}(\mathrm{~S})$. Background count times for the elements were $50 \%$ of their peak counting times. Replicate analysis of two basaltic glass check standards (FR:ND-60-01 (5), MR:ND-70-01 (5)) yielded average $2 \mathrm{RSDs}$ of less than $4 \%$ for major elements $\mathrm{SiO}_{2}, \mathrm{Al}_{2} \mathrm{O}_{3}, \mathrm{FeO}$, $\mathrm{MgO}$, and $\mathrm{CaO}$. Average $2 \mathrm{RSDs}$ for $\mathrm{K}_{2} \mathrm{O}, \mathrm{TiO}_{2}, \mathrm{Na}_{2} \mathrm{O}, \mathrm{S}$, and $\mathrm{Cl}$ were in the $10 \%-15 \%$ range while $\mathrm{MnO}$ and $\mathrm{P}_{2} \mathrm{O}_{5}$ were $25 \%$. Sulfur and chlorine are within $22 \%$ and $14 \%$ of the NanoSIMS measurements, respectively. Because we later model the $S$ profile in detail, we note that the electron probe and NanoSIMS profiles largely overlap, after adjustment for the $15-20 \%$ offsets (see Supplementary Table 2). We use the NanoSIMS data below in all figures and calculations, because the precision is better, and all volatiles are measured in the same spots.

\section{Results}

\subsection{Melt embayment morphology}

We report analyses of four olivine-hosted melt embayments from the October 17, 1974 Fuego eruption: two from the ash sample (VF-132), one from lapilli (VF-129), and one from the small bomb (VF-137B). The sample names for each embayment have been shortened and are represented in the following way, in ascending order of length: E1 (VF-129-E2), E2 (VF-132-E1), E3 (VF-132-E4), and E4 (VF-137B-E1). The four embayments display a range in size $(100-200 \mu \mathrm{m})$ and shape (Fig. 1), but all exhibit well-quenched glass with no evidence of co-entrapped phases or daughter crystals. Although not all of the embayments terminate on polyhedral crystal faces (Fig. 1), all exhibit evidence of matrix glass adjacent to the outlet bubble, indicating that the embayment was communicating with the surrounding melt. Additionally, all reported embayments were straight enough to justify one-dimensional diffusion modeling. The rounded edges of the embayment interiors suggest that they were formed through some slow-growth mechanism and are not remnants of healed grain boundaries (Faure and Schiano, 2005). The most important characteristic shared among all four embayments is a bubble at the outlet of the tube (Fig. 1).

Some distinctions need to be made in the terminology for the distances reported. The outlet refers to the gap in the host olivine where the contents (melt or gas) of the embayment interact with the surrounding magma. The distance to the bubble is the distance from an analysis point to the termination of the glass (start of the bubble) and does not take into account the embayment outlet. Although three of the embayments were straightforward to interpret in this way, E1 presented challenges because it was not polished at the maximum cross section of the bubble. A transmitted-light photomicrograph of the embayment (Supplementary Table 3) was used to measure the distance to the bubble in three dimensional space, which resulted in a shift of $7 \mu \mathrm{m}$ from the distances apparent in Fig. 1.

As the exterior and interior melt degas during decompression, the outlet bubbles are potentially undergoing dynamic changes in their size and shape that may limit the amount of glass that remains in the embayment. Although the distance from the terminus of the glass in the embayment to the outlet (i.e. the size of the bubble) varies, we assume that the melt in the embayment is in the process of re-equilibrating with the decompressing bubble and that the distance to the outlet from the 

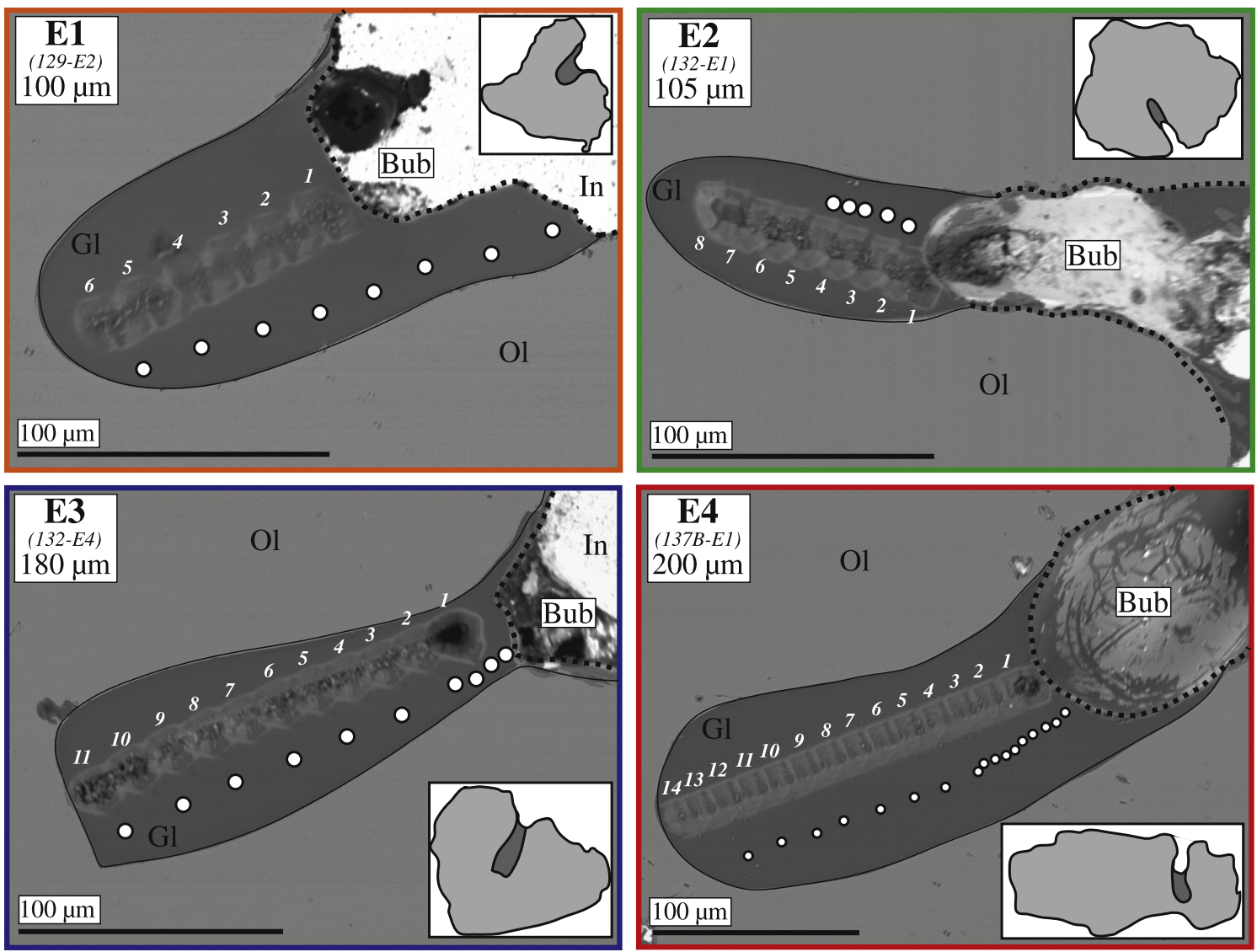

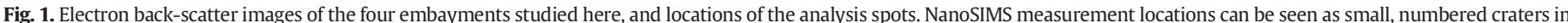

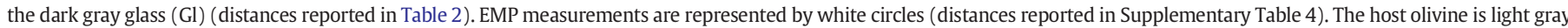

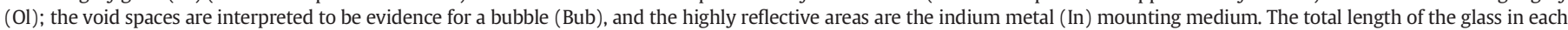

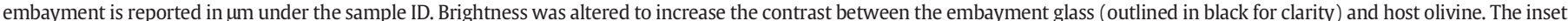
sketches show the size and location of the embayment relative to the host phenocryst.

terminus of the glass is not relevant for modeling the decompression rate. Changes in bubble size could lead to a moving boundary problem. However, the relative incompressibility of the internal melt in comparison to the ability of the bubble to freely expand into the surrounding matrix may reduce this possibility. For simplicity and the lack of evidence for a moving or deforming boundary, we assume that the initial volume of melt in the embayment is conserved throughout decompression.

\subsection{Major element variations in embayments}

The olivines that host the studied embayments have forsterite contents (72-75) that are similar to those measured previously from this day of the eruption (72-78; Lloyd et al., 2013). Assuming an $\mathrm{Fe}^{3+} / \Sigma \mathrm{Fe}$ ratio of 0.20 and a $K_{D}=0.35$ (as in Lloyd et al., 2013), the highest $\mathrm{Mg} \#$ measured in the glass for each embayment is in equilibrium with the host olivine, except for E1, which may have experienced $\sim 5 \%$ of post-entrapment crystallization, presumably at the interface between melt and host olivine. Because we are primarily concerned with volatile species in the melt embayment, no corrections to the major-element concentrations were applied for this crystallization.

The concentration of major elements in the inner regions of the embayments is uniform (within the error of the EMP measurements), and falls within one standard deviation of previous measurements in MIs for this day of the eruption (Table 1; Lloyd et al., 2013). $\mathrm{TiO}_{2}$ and $\mathrm{CaO}$ (and to a lesser extent $\mathrm{Al}_{2} \mathrm{O}_{3}$ ) are exceptions, with concentrations consistently higher than what is measured in the MIs. Similar to previous studies, the measured compositions classify the Fuego melts as a highalumina basaltic andesite.

In the 20-40 $\mu \mathrm{m}$ approaching the exit bubble, all embayments show concentration gradients (illustrated in Fig. 2 for E4, but also present for all embayments; see Supplementary Table 4 for all EMP analyses). The length of this chemical boundary layer varies among the four

Table 1

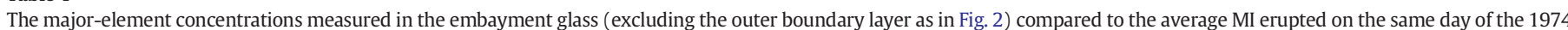

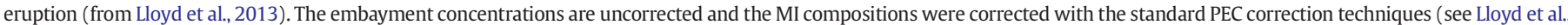
2013).

\begin{tabular}{|c|c|c|c|c|c|c|c|c|c|c|c|c|}
\hline Sample distance & & $\mathrm{SiO}_{2}$ & $\mathrm{TiO}_{2}$ & $\mathrm{Al}_{2} \mathrm{O}_{3}$ & $\mathrm{FeO}^{\mathrm{T}}$ & $\mathrm{MnO}$ & $\mathrm{MgO}$ & $\mathrm{CaO}$ & $\mathrm{Na}_{2} \mathrm{O}$ & $\mathrm{K}_{2} \mathrm{O}$ & $\mathrm{P}_{2} \mathrm{O}_{5}$ & Total \\
\hline Average MI (1 SD) & & $52.07(2.51)$ & $1.06(0.13)$ & $17.10(0.89)$ & $9.28(0.73)$ & $0.15(0.03)$ & $4.16(0.46)$ & $7.47(0.96)$ & $3.70(0.41)$ & $0.86(0.18)$ & $0.25(0.05)$ & $96.29(1.03)$ \\
\hline El-7 & 60 & 51.97 & 1.23 & 17.97 & 9.99 & 0.20 & 3.69 & 8.71 & 3.74 & 0.87 & 0.20 & 99.00 \\
\hline E2-5 & 28 & 52.73 & 1.27 & 18.21 & 9.99 & 0.16 & 3.56 & 8.79 & 4.03 & 1.04 & 0.21 & 100.44 \\
\hline E3-8 & 115 & 51.94 & 1.20 & 17.74 & 9.76 & 0.18 & 4.09 & 8.62 & 3.70 & 0.81 & 0.21 & 98.70 \\
\hline E4-15 & 127 & 50.90 & 1.22 & 17.80 & 10.02 & 0.19 & 4.23 & 8.63 & 3.96 & 0.81 & 0.19 & 98.39 \\
\hline
\end{tabular}




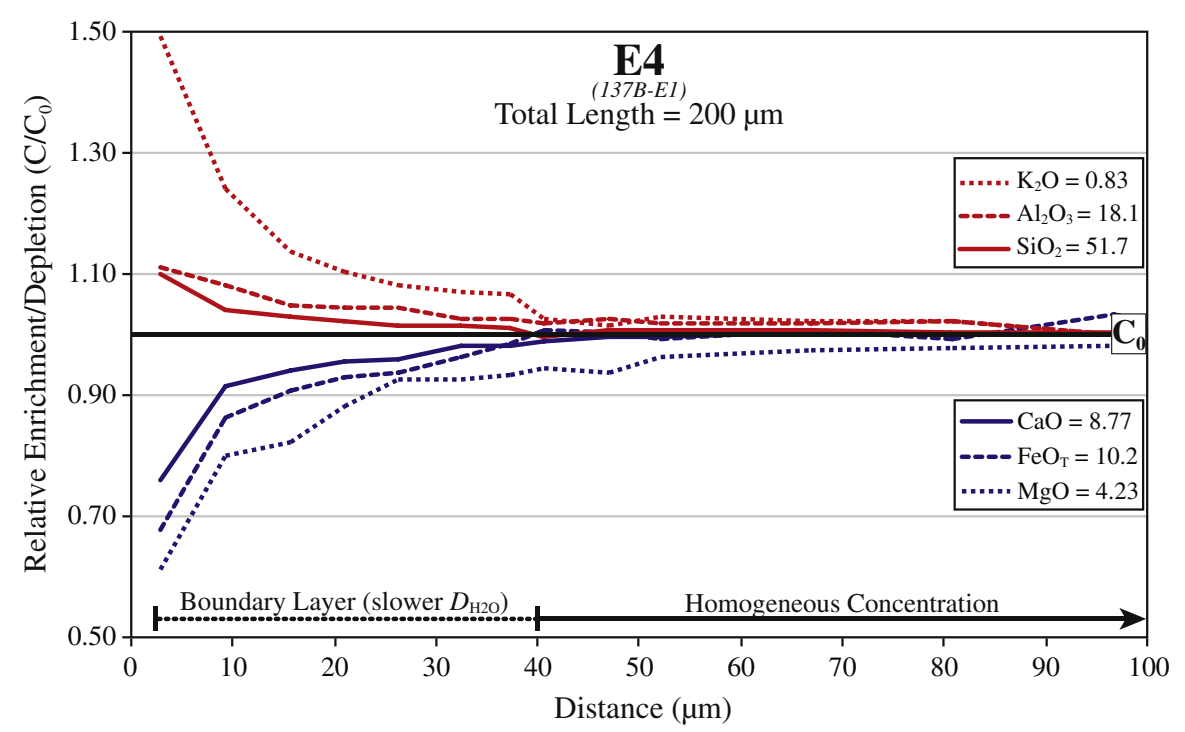

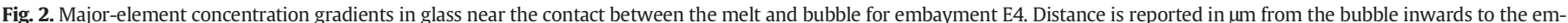

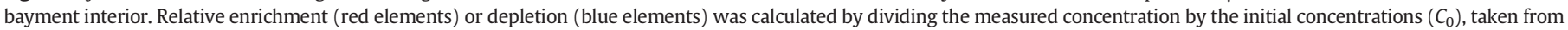

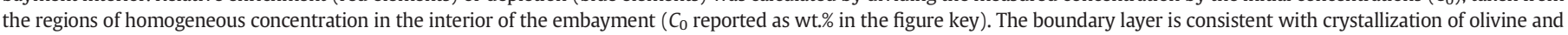

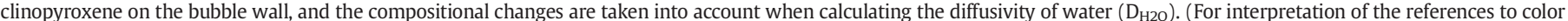
in this figure legend, the reader is referred to the web version of this article.)

embayments and differs in shape depending upon the element in question. The magnitude of enrichment or depletion in this boundary layer appears to be dependent on the compatibility of the element (i.e., greatest enrichment for the most incompatible element, $\mathrm{K}_{2} \mathrm{O}$, and greatest depletion for most compatible, $\mathrm{MgO}$ ). On the other hand, the length of the boundary layer decreases in the order $\mathrm{K}_{2} \mathrm{O}, \mathrm{CaO}, \mathrm{FeO}$, $\mathrm{MgO}, \mathrm{Al}_{2} \mathrm{O}_{3}$, and $\mathrm{SiO}_{2}$ (from 40 to $20 \mu \mathrm{m}$ respectively; Fig. 2), which is in agreement with the elements' respective rates of diffusion in mafic melt (Zhang et al., 2010). The components $\mathrm{MgO}$, FeO, and $\mathrm{CaO}$ behave compatibly and decrease in concentration toward the bubble; whereas, $\mathrm{SiO}_{2}, \mathrm{Al}_{2} \mathrm{O}_{3}$, and $\mathrm{K}_{2} \mathrm{O}$ increase toward the bubble (Fig. 2). These patterns are consistent with the crystallization of primarily olivine as well as clinopyroxene but not plagioclase, which is the most abundant phase in the eruptive products (perhaps reflecting an inability of plagioclase to nucleate on the bubble wall in the embayment). Observed under transmitted or reflected light (Fig. 1 and Supplementary Table 3), there is no observable crystallization within the vitrified embayment glass or on the bubble/glass interface. Mass-balance calculations of the observed decrease in $\mathrm{MgO}, \mathrm{FeO}$, and $\mathrm{CaO}$ indicate that any potential crystal growth would be less than $2 \mu \mathrm{m}$ in thickness, so any visible evidence for crystallization may be difficult to resolve with optical microscopy. It should be noted that this compositional boundary layer observed in the Fuego embayments precludes the use of the backscattered electron (BSE) method used in Humphreys et al. (2008) to estimate $\mathrm{H}_{2} \mathrm{O}$ concentration, because the major-element variations dominate over the $\mathrm{H}_{2} \mathrm{O}$ variations in controlling BSE gray scale intensity.

\subsection{Volatile concentrations in embayments}

In all four embayments, $\mathrm{CO}_{2}, \mathrm{H}_{2} \mathrm{O}$, and $\mathrm{S}$ decrease in concentration toward the outlet bubble, whereas $\mathrm{Cl}$ and $\mathrm{F}$ vary little throughout the embayments (Fig. 3; Table 2). The concentrations in these embayments differ considerably from fully-enclosed melt inclusions, most notably $\mathrm{H}_{2} \mathrm{O}$ (Fig. 3A). For example, $\mathrm{H}_{2} \mathrm{O}$ concentrations in the embayments are uniformly $<3 \mathrm{wt} . \%$, while those in the melt inclusions from the ash and lapilli samples are uniformly $>3$ wt.\%. The only MIs that overlap in $\mathrm{H}_{2} \mathrm{O}$ with the embayments originate from more slowly cooled bomb samples (indicated by dark gray in Fig. 3) that appear to have lost $\mathrm{H}_{2} \mathrm{O}$ by diffusion through their host olivine (Lloyd et al., 2013). The two longest embayments ( $\mathrm{E} 3$ and $\mathrm{E} 4$ ) have the highest $\mathrm{H}_{2} \mathrm{O}$ concentrations, whereas the two shorter embayments (E2 and E1) have lower concentrations at similar distances from the bubble, consistent with diffusive $\mathrm{H}_{2} \mathrm{O}$-loss. All of the embayment concentrations, however, are greater than the highly degassed values measured in the groundmass glass $(<0.06$ wt.\%; see Supplementary Table 5).

$\mathrm{CO}_{2}$ also decreases toward the bubble (Fig. 3B), again, with the two longest embayments having higher maximum $\mathrm{CO}_{2}$ concentrations than the shorter embayments. The $\mathrm{CO}_{2}$ concentration gradient for $\mathrm{E} 2$ is shallower than in the other embayments (Fig. 3B). While the MIs have a narrow range in $\mathrm{H}_{2} \mathrm{O}$ concentrations (3-4 wt.\%), $\mathrm{MI} \mathrm{CO}$ concentrations vary over a much wider range (100-750 ppm). With fewer than $20 \%$ of the MI analyses overlapping with the maximum measured $\mathrm{CO}_{2}$ in the embayments (Fig. 3B), it is unlikely that the interior of the embayments represents the initial concentration of $\mathrm{CO}_{2}$. Previous work was unable to report $\mathrm{CO}_{2}$ concentrations in the Fuego groundmass glass due to contamination (Lloyd et al., 2013), but they are likely to be lower than the lowest concentrations recorded in the embayments.

Sulfur also decreases toward the bubble, but unlike $\mathrm{H}_{2} \mathrm{O}$ and $\mathrm{CO}_{2}$, the $S$ concentrations of the interior of all four embayments fall within the peak of the MI population (1250-2250 ppm, Fig. 3C). The embayment interiors thus appear to retain initial $S$ concentrations that are unaffected by diffusive loss, consistent with the relative diffusivities of $\mathrm{H}_{2} \mathrm{O}, \mathrm{CO}_{2}$, and $S$ (Baker et al., 2005). Three embayments continually decrease in $S$, whereas E3 (and E2 to a lesser extent) shows a complex pattern of increasing and then decreasing S toward the exterior (Fig. 3C). The S concentrations in the groundmass glass are lower than the lowest recorded in the embayments.

The concentrations of $\mathrm{Cl}$ in the embayments largely overlap with those of the MI population, albeit occupying the enriched end of the MI spectrum. Moreover, throughout the length of the embayment, $\mathrm{Cl}$ remains relatively constant. This contrast in the behavior of $\mathrm{Cl}$ relative to $\mathrm{H}_{2} \mathrm{O}, \mathrm{CO}_{2}$ and $\mathrm{S}$ may reflect its lack of partitioning into a vapor phase over much of the magma ascent path. Indeed, $\mathrm{Cl}$ varies inversely with $\mathrm{H}_{2} \mathrm{O}$ and $\mathrm{S}$ in Fuego MIs, rising in concentration during degassing like a magmaphile element (Lloyd et al., 2013). Nonetheless, the Cl concentration in the Fuego groundmass glass is notably lower than the MIs or embayments, and likely reflects degassing of $\mathrm{Cl}$ at pressures lower than those recorded in the MIs (i.e., $<150 \mathrm{MPa}$ ). Degassing may also be recorded in the analysis point closest to the embayment bubbles 

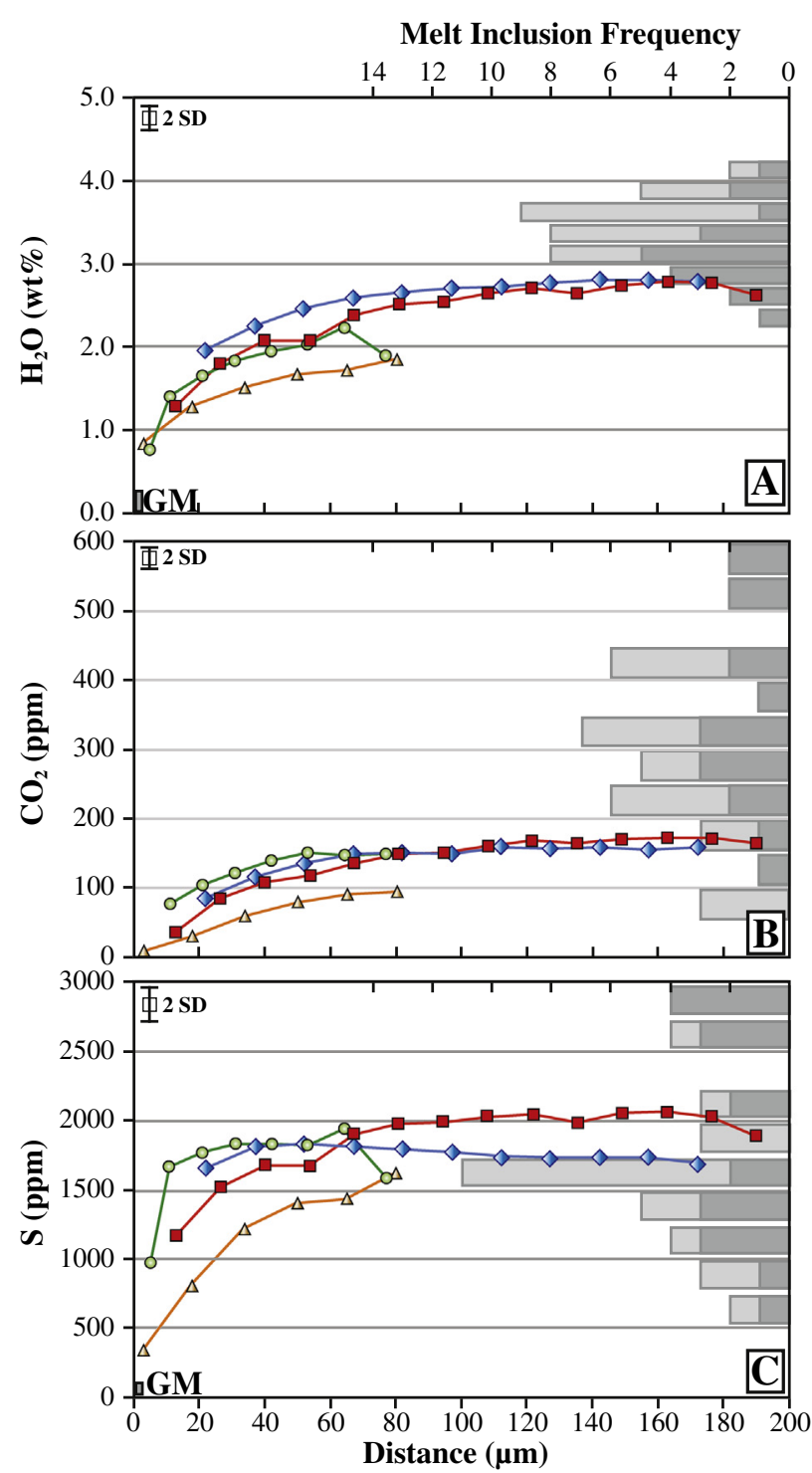

Melt Inclusion Frequency
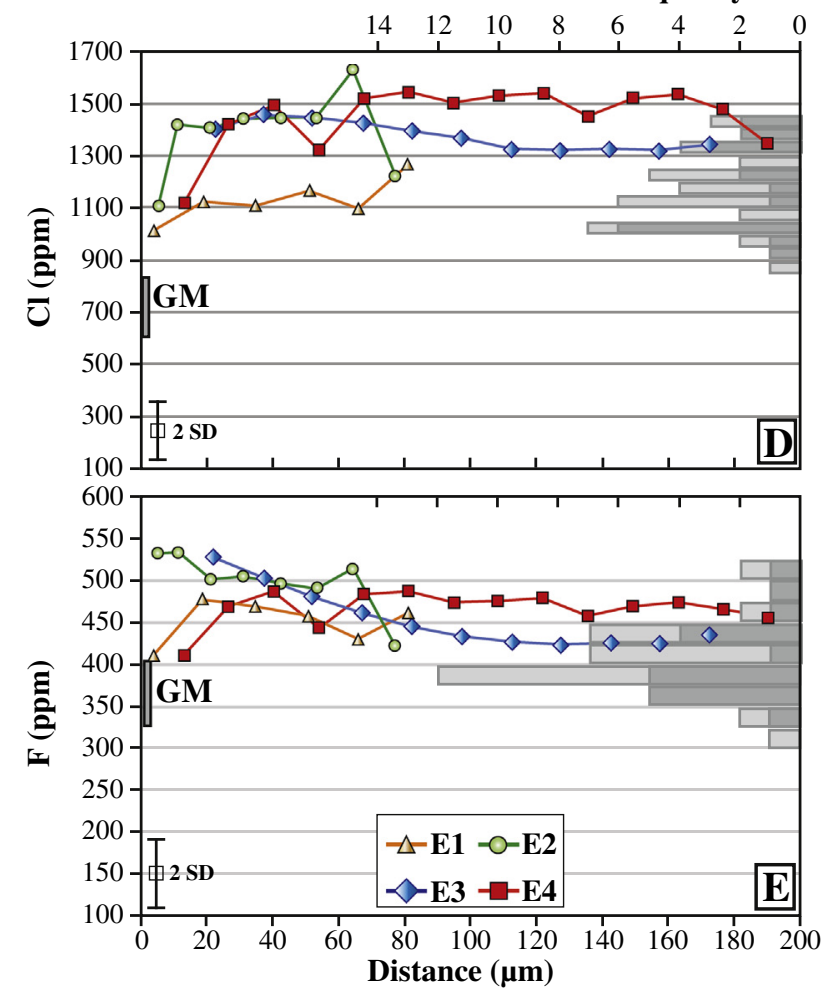

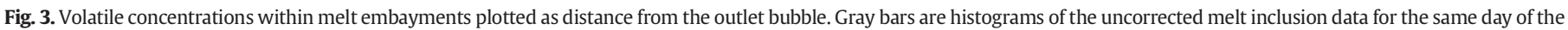

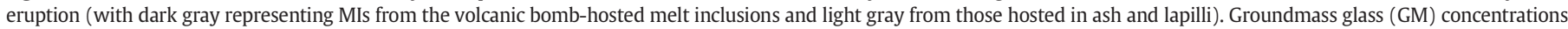
(Supplementary Table 5) are plotted at zero distance for reference.

(between 6 and $22 \mu \mathrm{m}$, Table 2), where $\mathrm{Cl}$ decreases abruptly (approximately 100 ppm for E1 and E3, or 300 ppm for E2 and E4).

The concentration of $\mathrm{F}$ in the embayments also largely overlaps with that in the MIs, but it shows inconsistent behavior along the embayments (Fig. 3E). In two cases (E3, E2), F increases smoothly by a factor of $\sim 1.2$ from the embayment interior to the bubble. The two other embayments (E4, E1) show a relatively flat concentration profile with a drop in concentration of $\sim 60 \mathrm{ppm}$ at the analysis spot closest to the bubble. $\mathrm{F}$ is the most magmaphilic of the volatile elements, with no evidence for degassing. This is apparent in the overlap in $\mathrm{F}$ between the groundmass glass (350-400 ppm) and the peak in the MI population (Fig. 3E).

\subsection{Coupled volatile-major element variations in embayments}

Fig. 4 plots the volatile elements, $\mathrm{H}_{2} \mathrm{O}, \mathrm{CO}_{2}, \mathrm{~S}$ and $\mathrm{Cl}$, vs. $\mathrm{SiO}_{2}$ in the embayments and the fully enclosed MIs from Lloyd et al. (2013). The $\mathrm{SiO}_{2}$ concentrations clump at low values in the uniform embayment interiors, and extend to high values within the 20-30 micron boundary layer near the bubble (i.e., as in Fig. 2). The embayment interiors plot at the low $\mathrm{SiO}_{2}$ and high $\mathrm{S}$ end of the MI array, consistent with an initial composition that coincides with the most primitive for the eruption. Lloyd et al. (2013) interpreted the MI array to reflect coupled degassing and crystallization during ascent, to explain the increase in $\mathrm{SiO}_{2}$ and decrease in S, for example. From this perspective, the embayments would reflect an origin early in the ascent history. Embayment interiors coincide with the MI array for $\mathrm{S}$, but fall well below the array for $\mathrm{H}_{2} \mathrm{O}$ and $\mathrm{CO}_{2}$. All of the embayment interiors are enriched in $\mathrm{Cl}$ at the same $\mathrm{SiO}_{2}$ as the MI, by up to $20-40 \%$. All of these variations (except $\mathrm{Cl}$ ) are consistent with loss of volatiles toward the vapor bubble, at the same time that crystallization around the bubble leads to an increase in $\mathrm{SiO}_{2}$. The different trajectories of the MI array and the embayment profiles likely result from different processes: diffusive loss of volatiles from the open embayments vs. entrapment of degassing melt at variable depths for the MIs. In the next section, we use these inferences along with a numerical diffusion model to describe the embayment profiles for $\mathrm{H}_{2} \mathrm{O}, \mathrm{CO}_{2}$ and $\mathrm{S}$. There may be further information in the behavior of $\mathrm{Cl}$ and major elements, but these appear to be complicated by multi-phase crystallization and other less well understood processes. 
Table 2

NanoSIMS results for the analyses shown in Fig. 1 ( $n d$, not detected). Distance is measured from the outlet bubble. See Supplementary Table 1 for calibration standards and error calculation.

\begin{tabular}{|c|c|c|c|c|c|c|}
\hline Analysis & $\begin{array}{l}\text { Dist. } \\
(\mu \mathrm{m})\end{array}$ & $\begin{array}{l}\mathrm{CO}_{2} \\
(\mathrm{ppm})\end{array}$ & $\begin{array}{l}\mathrm{H}_{2} \mathrm{O} \\
\text { (wt.\%) }\end{array}$ & $\begin{array}{l}\mathrm{F} \\
(\mathrm{ppm})\end{array}$ & $\begin{array}{l}\mathrm{S} \\
(\mathrm{ppm})\end{array}$ & $\begin{array}{l}\mathrm{Cl} \\
(\mathrm{ppm})\end{array}$ \\
\hline E1-1 & 2 & 9 & 0.83 & 411 & 335 & 1011 \\
\hline $\mathrm{E} 1-2$ & 17 & 32 & 1.28 & 477 & 814 & 1124 \\
\hline E1-3 & 33 & 61 & 1.51 & 469 & 1224 & 1109 \\
\hline E1-4 & 49 & 79 & 1.67 & 458 & 1410 & 1164 \\
\hline E1-5 & 64 & 91 & 1.72 & 431 & 1439 & 1098 \\
\hline E1-6 & 79 & 96 & 1.85 & 461 & 1620 & 1265 \\
\hline E2-1 & 5 & $n d$ & 0.76 & 532 & 982 & 1105 \\
\hline E2-2 & 11 & 78 & 1.42 & 534 & 1667 & 1419 \\
\hline $\mathrm{E} 2-3$ & 21 & 105 & 1.66 & 503 & 1777 & 1406 \\
\hline E2-4 & 31 & 123 & 1.83 & 504 & 1832 & 1442 \\
\hline E2-5 & 42 & 139 & 1.95 & 497 & 1838 & 1444 \\
\hline E2-6 & 53 & 151 & 2.02 & 491 & 1827 & 1444 \\
\hline E2-7 & 64 & 148 & 2.24 & 514 & 1945 & 1628 \\
\hline E2-8 & 77 & 150 & 1.89 & 422 & 1591 & 1220 \\
\hline E3-1 & 22 & 86 & 1.95 & 527 & 1659 & 1407 \\
\hline E3-2 & 37 & 116 & 2.26 & 504 & 1821 & 1457 \\
\hline E3-3 & 52 & 137 & 2.46 & 480 & 1835 & 1445 \\
\hline E3-4 & 67 & 149 & 2.59 & 462 & 1821 & 1424 \\
\hline E3-5 & 82 & 152 & 2.66 & 445 & 1793 & 1394 \\
\hline E3-6 & 97 & 150 & 2.70 & 434 & 1775 & 1366 \\
\hline E3-7 & 112 & 159 & 2.73 & 427 & 1746 & 1327 \\
\hline E3-8 & 127 & 158 & 2.78 & 424 & 1744 & 1323 \\
\hline E3-9 & 142 & 159 & 2.80 & 425 & 1742 & 1324 \\
\hline E3-10 & 157 & 155 & 2.81 & 425 & 1735 & 1321 \\
\hline E3-11 & 172 & 160 & 2.78 & 435 & 1704 & 1341 \\
\hline E4-1 & 13 & 37 & 1.28 & 411 & 1177 & 1120 \\
\hline E4-2 & 27 & 85 & 1.80 & 469 & 1528 & 1418 \\
\hline E4-3 & 40 & 108 & 2.07 & 487 & 1686 & 1492 \\
\hline E4-4 & 54 & 119 & 2.07 & 444 & 1679 & 1321 \\
\hline E4-5 & 67 & 136 & 2.38 & 484 & 1907 & 1517 \\
\hline E4-6 & 81 & 150 & 2.51 & 487 & 1982 & 1544 \\
\hline E4-7 & 95 & 152 & 2.54 & 475 & 1996 & 1506 \\
\hline E4-8 & 108 & 162 & 2.63 & 476 & 2035 & 1531 \\
\hline E4-9 & 122 & 168 & 2.71 & 478 & 2055 & 1542 \\
\hline E4-10 & 135 & 166 & 2.65 & 459 & 1991 & 1452 \\
\hline E4-11 & 149 & 171 & 2.74 & 469 & 2062 & 1521 \\
\hline E4-12 & 163 & 173 & 2.79 & 474 & 2073 & 1533 \\
\hline E4-13 & 176 & 173 & 2.76 & 466 & 2032 & 1476 \\
\hline E4-14 & 190 & 165 & 2.62 & 456 & 1892 & 1348 \\
\hline
\end{tabular}

\section{Discussion}

\subsection{Diffusion modeling}

In order to use the volatile concentrations as chronometers for magma ascent, several parameters must be known in order to constrain the time during which diffusion took place: the initial conditions prior to decompression; the changing external melt during ascent, and the diffusivity of each volatile species. The concentration profiles are modeled using a one-dimensional diffusion model that evolves during decompression and coeval magma degassing:

$\partial C_{i} / \partial t=\partial / \partial x\left[D_{i}(C) \partial C_{i} / \partial x\right]$

where $C$ and $D$ are the elemental concentrations in the embayment and the diffusion coefficient, respectively, and subscript $i$ refers to the different volatile species. The diffusion equation is solved via a finite-volume approach. We assume that the diffusive volatile transfer is the only mass exchange in the embayment and that the host phenocryst does not undergo any further growth or exchange. The model is isothermal with a temperature of $1030{ }^{\circ} \mathrm{C}$, based on olivine liquid thermometry between the MIs and host phenocrysts (Lloyd et al., 2013). In modeling the $\mathrm{H}_{2} \mathrm{O}, \mathrm{CO}_{2}$ and $\mathrm{S}$ profiles, we take into account the effect of changing major-element composition on volatile diffusivities within the outer 20-40 micron chemical boundary layer adjacent to the bubble (e.g., Fig. 2). The diffusivities of all the volatile species are also dependent on water concentration. We assume that diffusive loss from the embayment occurs only through the embayment outlet at the glass/bubble interface $(x=0)$. This assumption results in pressure- and timedependent boundary conditions at the embayment exterior, while zeroflux conditions are prescribed at the inner-end of the embayment and distance $L$ from the bubble. It is also assumed that the melt at the embayment terminus (i.e., adjacent to the vapor bubble), and the surrounding magma remains in equilibrium throughout the degassing process. We assume that the fully enclosed MIs trap melt at different depths in the conduit (Lloyd et al., 2013), and so define the degassing path taken by the melt exterior to the embayments. Diffusion is assumed to cease at a final pressure $\left(P_{F}\right)$ at the time $t_{F}$ when the magma abruptly cools, preserving the observed volatile zoning pattern:

$C_{0, t}=C_{\text {matrix }}(p, t)$,

$C_{0, t F}=C_{\text {matrix }}\left(P_{F}, t_{F}\right)$,

$\partial C_{L, t} / \partial x=0$

$C_{\text {matrix }}(p, t)$ is the volatile concentration of the matrix glass, which is pressure-dependent and, through the decompression rate, also timedependent. As in previous embayment studies (Humphreys et al., 2008), we make the important assumption that the matrix melt is undergoing equilibrium degassing, consistent with the MI array (Lloyd et al., 2013). Prior to ascent, volatile species have flat profiles in the embayments and are in equilibrium with the matrix melt leading to the following initial conditions:

$C_{x, 0}=C_{\text {matrix }}\left(P_{0}\right)$,

with $C_{\text {matrix }}\left(P_{0}\right)$ referring to the volatile concentration in the matrix at the initial pressure prior to ascent $\left(P_{0}\right)$. The free parameters in this model that can be varied are the initial and final pressures, which control the initial and evolving exterior melt concentrations for all volatiles through a multi-element degassing model that is presented below. The other independent variable from these diffusion models is the decompression rate. Changes in the decompression rate $\mathrm{dP} / \mathrm{d} t$ affect the shape of the diffusion profile and the extent of whole-embayment equilibration. Instead of iterating through many combinations of various $P_{0}, P_{F}$, and $\mathrm{d} p / \mathrm{d} t$, we constrain narrow bounds for reasonable $P_{0}$ and $P_{F}$ through the embayment and MI volatile record as well as the multi-element degassing model, leaving only $\mathrm{d} P / \mathrm{d} t$ as the primary free variable. We refined the grid spacing to between 1 and $2 \mu \mathrm{m}$ after which no noticeable differences in the model results were observed. We use an implicit iteration scheme, which allows us to obtain accurate results even for large time stepping. However, to capture the time-dependent nature of the outlet boundary condition we use 200 time-steps. Further increases in the number of time-steps do not result in significantly different model outputs.

\subsection{Fixing the initial and final pressures of magma degassing}

One of the most essential starting conditions to define is the initial pressure $\left(P_{0}\right)$ from where an embayment begins its ascent path. $P_{0}$ represents the starting pressure for the diffusion clock and ultimately determines the total distance the phenocryst travels from storage to eruption. $P_{0}$ may represent either the pressure of embayment formation during isobaric crystallization, or the pressure where the embayment last equilibrated with the external melt.

While choosing $P_{0}$ from the embayment records is non-unique, the MI population provides some guidance to the pressure range over which rapid crystal growth occurred. Inherent in this assumption is that embayments represent failed MIs and that both presumably share a common ascent history. Melt inclusions remain the premier tool for 

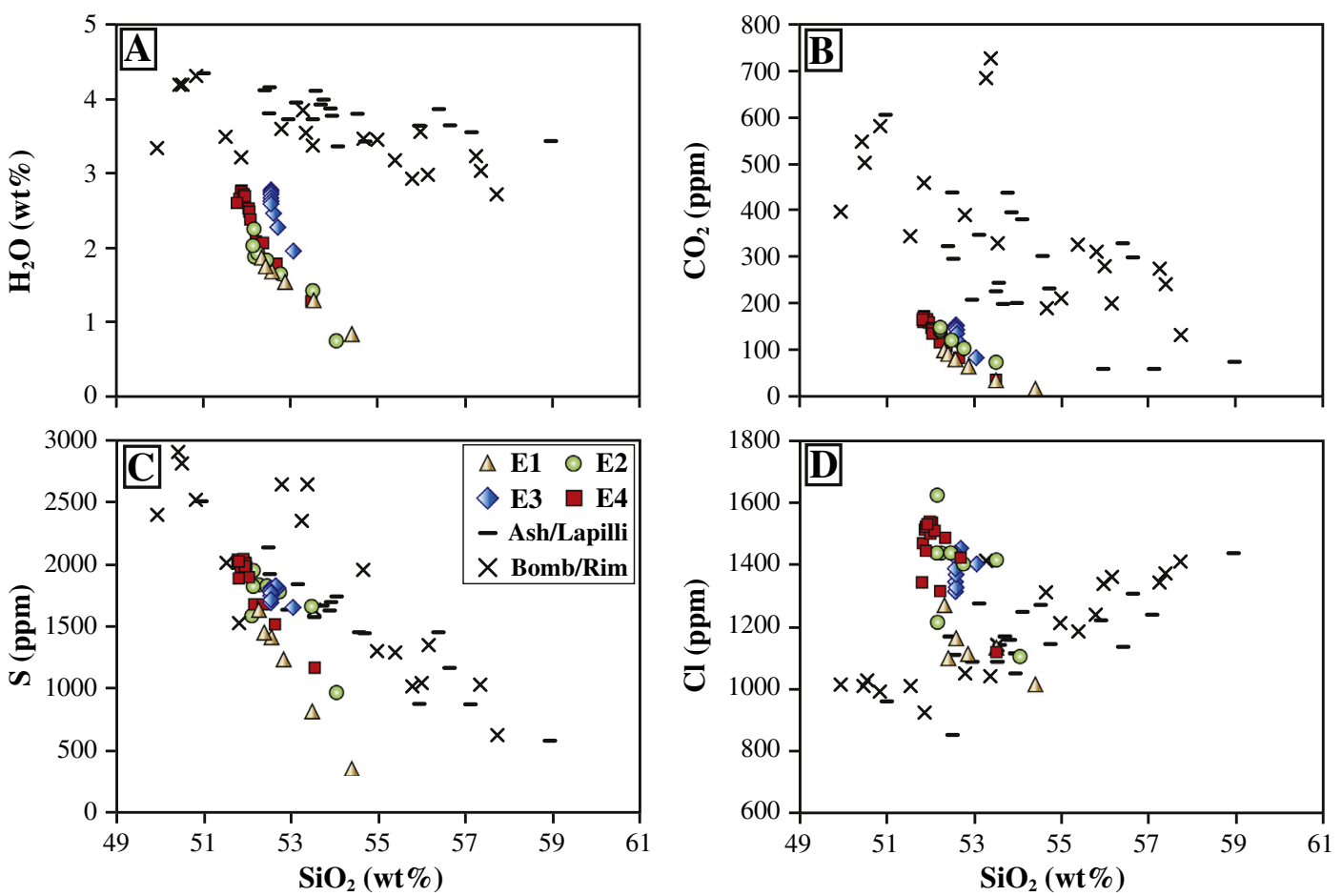

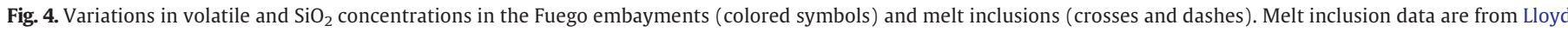

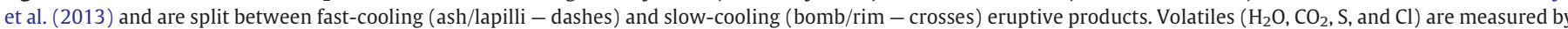

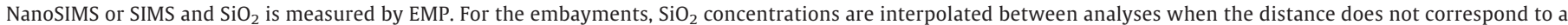
NanoSIMS measurement location. (For interpretation of the references to color in this figure legend, the reader is referred to the web version of this article.)

tracking the degassing pathways for mafic magmas, despite their complexities (Metrich and Wallace, 2008). Some of the Fuego MIs, notably those derived from bomb-sized clasts and other small ones from lapilli, suffered $\mathrm{H}_{2} \mathrm{O}$-loss as a function of diffusive re-equilibration through the olivine host to the exterior degassing melt during ascent and/or posteruptive cooling (Lloyd et al., 2013). These inclusions were corrected for $\mathrm{H}_{2} \mathrm{O}$-loss based on their $\mathrm{K}_{2} \mathrm{O}$ content, and a model for coupled degassing and crystallization derived from the large, ash hosted MI and a numerical petrological model (Lloyd et al., 2013). When corrected, all of the Fuego MIs define a trend consistent with closed-system, vaporsaturated, equilibrium degassing path for $\mathrm{H}_{2} \mathrm{O}, \mathrm{CO}_{2}$ and $\mathrm{S}$ (Fig. 5). The embayments fall off the closed-system degassing path due to substantial diffusive volatile loss of $\mathrm{H}_{2} \mathrm{O}$ and $\mathrm{CO}_{2}$, even from the interior of the embayments (Fig. 5A). On the other hand, the embayment interiors appear to retain their initial sulfur concentrations, as is evident in their overlap with the MI array (Figs. 3C and 4C). This is consistent with the lower diffusivity of sulfur compared to $\mathrm{H}_{2} \mathrm{O}$ and $\mathrm{CO}_{2}$ (see below) and hence potential to record $P_{0}$. We assume that the highest sulfur concentration in the embayments is representative of its initial value and, when combined with the $\mathrm{H}_{2} \mathrm{O}-\mathrm{CO}_{2}$ and $\mathrm{H}_{2} \mathrm{O}-\mathrm{S}$ degassing path recorded in the MIs, constrains $P_{0}$ for the embayments. We develop a Fuego-specific, pressure-dependent $\mathrm{H}_{2} \mathrm{O}-\mathrm{CO}_{2}-\mathrm{S}$ degassing model (Fig. 6) by combining a $\mathrm{H}_{2} \mathrm{O}-\mathrm{CO}_{2}$ closed-system model (using a starting pressure of $400 \mathrm{MPa}$ calculated from SolEx, Witham et al., 2012; Fig. 5A) with the $\mathrm{H}_{2} \mathrm{O}-\mathrm{S}$ degassing model (Fig. 5B) calculated in Lloyd et al. (2013). Essentially, these two degassing models are tied together through the $\mathrm{H}_{2} \mathrm{O}$ content in the melt, and guided by the MI array. The combined model enables us to find a unique $P_{0}$ (and thus initial dissolved $\mathrm{H}_{2} \mathrm{O}$ and $\mathrm{CO}_{2}$ concentrations) for each embayment using the highest measured sulfur.

The pressure-dependent $\mathrm{H}_{2} \mathrm{O}-\mathrm{CO}_{2}-\mathrm{S}$ degassing model was also utilized to constrain the external melt at the embayment outlet during ascent and decompression (Fig. 6). The deeper part (>150 MPa) of the closed-system degassing path is well constrained through the MI record
(Fig. 5A) and is primarily in the domain of $\mathrm{CO}_{2}$ degassing. At pressures lower than $150 \mathrm{MPa}$, the degassing model mostly relies on the SolEx output as the MI record becomes sparse.

The final pressure $\left(P_{F}\right)$ is interpreted to be the pressure at which the embayment glass quenches, presumably at shallow depths in the upper conduit (Humphreys et al., 2008). $\mathrm{H}_{2} \mathrm{O}$ concentrations near the bubble and in the matrix glass provide the most robust constraint for $P_{F}$, since $\mathrm{H}_{2} \mathrm{O}$ degassing continues to very low pressures (Fig. 6). The minimum $\mathrm{H}_{2} \mathrm{O}$ measured in the embayments is 0.76 wt.\% (sample 131-E1) corresponding to a pressure of $6 \mathrm{MPa}$, based on SolEx (this is an upper limit as $\mathrm{H}_{2} \mathrm{O}$ was measured $\sim 5 \mu \mathrm{m}$ from the bubble in an area of a steep concentration gradient). The four embayments show similar $\mathrm{H}_{2} \mathrm{O}$-profiles approaching the bubble, consistent with equilibrating lastly with a melt containing $\sim 0.4 \mathrm{wt} . \% \mathrm{H}_{2} \mathrm{O}\left(P_{F} \sim 2 \mathrm{MPa}\right)$, which is higher than the concentration of $\mathrm{H}_{2} \mathrm{O}$ measured in the degassed groundmass glass (0.042-0.057 wt.\% $\mathrm{H}_{2} \mathrm{O}$; Supplementary Table 5).

\subsection{Volatile diffusivity}

Any diffusion chronometer depends critically on the diffusivity for the species of interest, which may vary as a function of temperature, pressure, and melt composition (Costa and Morgan, 2010; Zhang and Cherniak, 2010). Below we outline the composition-dependent diffusion coefficients that we use specific to the Fuego basaltic andesitic melts at a constant temperature of $1030{ }^{\circ} \mathrm{C}$.

The diffusivity of $\mathrm{H}_{2} \mathrm{O}$ in silicate melt is relatively well-characterized in comparison to the other volatile species (Zhang and Ni, 2010 and references therein). The temperature dependence of $\mathrm{H}_{2} \mathrm{O}$ is defined by an Arrhenius relationship with similar activation energy for different magma compositions (Fig. 7). We ignore pressure effects on the diffusivity of $\mathrm{H}_{2} \mathrm{O}$, which are minor for intermediate to mafic melt compositions like at Fuego (Behrens et al., 2004; Zhang and Ni, 2010). $D_{\mathrm{H} 2 \mathrm{O}}$ in silicate melt is known to be strongly dependent on melt composition, 

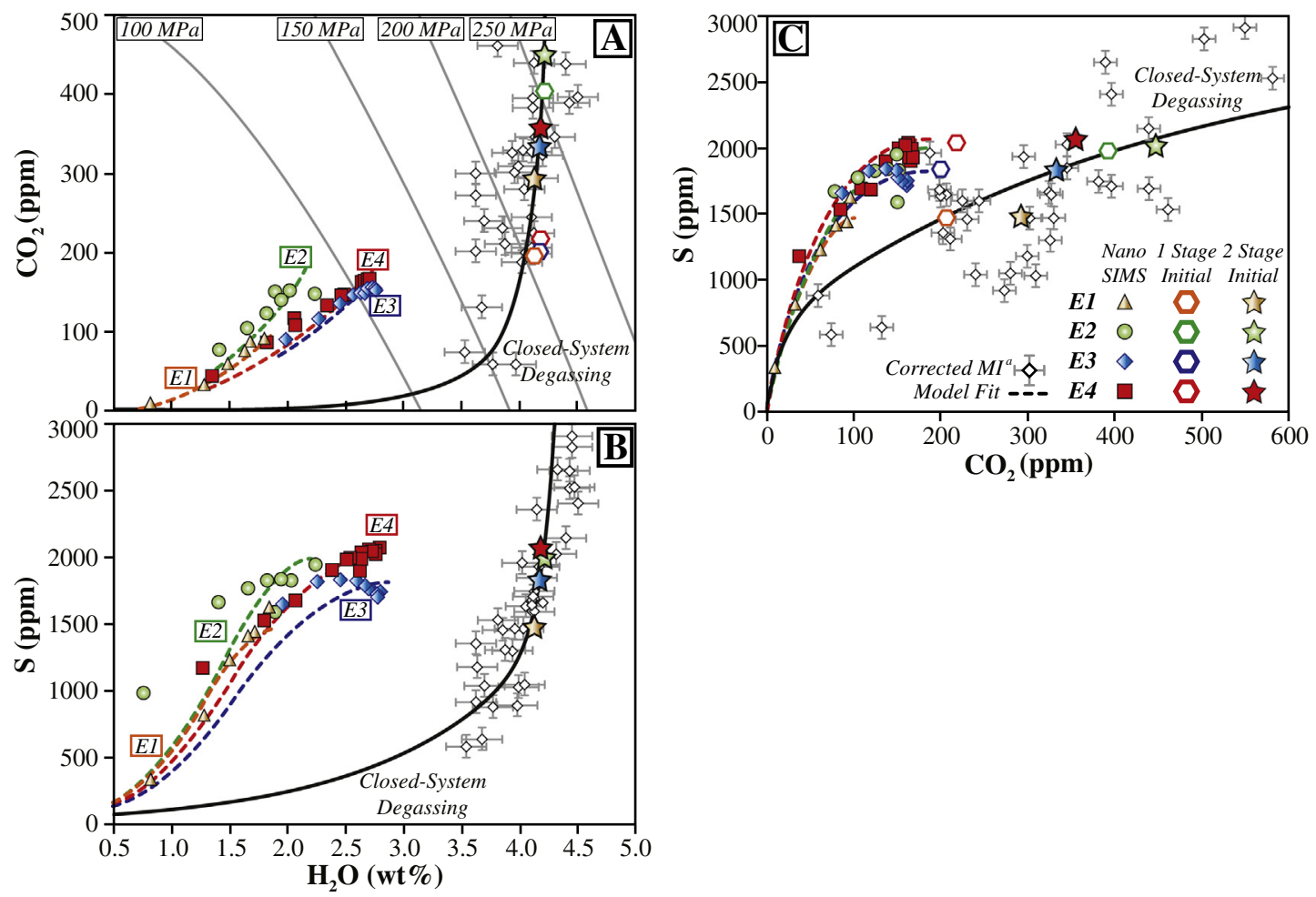

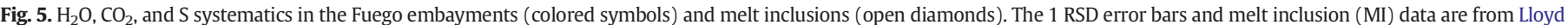

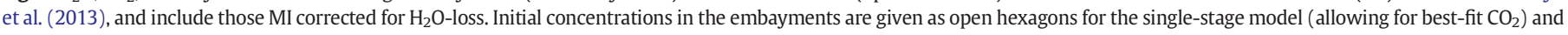

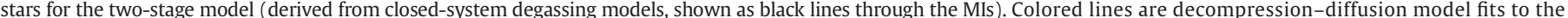

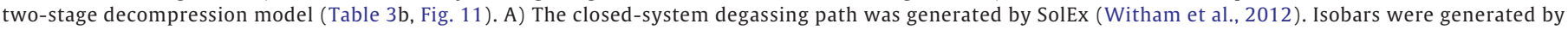

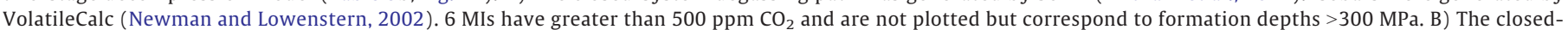

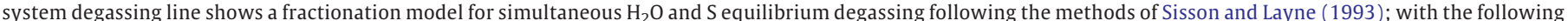

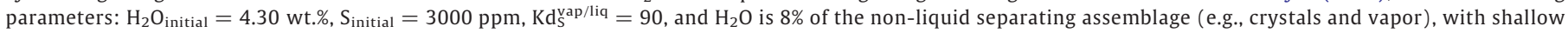

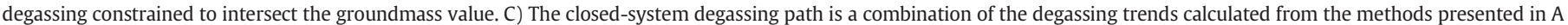
and $\mathrm{B}$. (For interpretation of the references to color in this figure legend, the reader is referred to the web version of this article.)

with diffusivities in basalt being a factor of 10 greater than in andesite at the same temperature (Fig. 7; Zhang and Ni, 2010). The embayments in this study fall within this compositional range, although a simple average is likely inadequate for the Fuego basaltic andesite. $D_{\mathrm{H} 2 \mathrm{O}}$ is primarily dependent on melt $\mathrm{SiO}_{2}$ content, however, alkaline components and non- $\mathrm{SiO}_{2}$ network formers are known to have significant effects as well (Okumura and Nakashima, 2006; Ni et al., 2013). Because Fuego erupts a high-alumina basaltic andesite, the effect of the $\mathrm{Al}_{2} \mathrm{O}_{3}$ concentration, in particular, needs to be assessed.

To account for the extent of melt polymerization, we parameterized $D_{\mathrm{H} 2 \mathrm{O}}$ using $\mathrm{NBO} / \mathrm{T}$, the ratio of non-bridging oxygen to tetrahedrally coordinated cations that act as network formers (calculated by methods outlined in Mysen and Richet, 2005). Although the average $\mathrm{SiO}_{2}$ concentration in the Fuego magma (52.8 wt.\%) is closer to typical basalts ( $\leq 52$ wt.\%) than andesites ( $\geq 57$ wt.\%), the NBO/T ratio indicates that melt polymerization for the Fuego embayments is more similar to the andesitic melt studied by Behrens et al. (2004) (Fig. 8). As shown previously (Fig. 2), the Fuego embayments are zoned in their major elements with greater melt polymerization (a decrease in NBO/T) near the bubble, effectively lowering $D_{\mathrm{H} 2 \mathrm{O}}$ at the outlet (Fig. 8). We approximate $D_{\mathrm{H} 2 \mathrm{O}}$ in Fuego embayments via a linear interpolation of $D_{\mathrm{H} 2 \mathrm{O}}$ and NBO/T between andesitic and basaltic melt (Fig. 8 inset). The four embayments show similar NBO/T zoning patterns that are fitted with a logarithmic regression as a function of distance from the bubble (see Fig. 8). In addition to adjusting $D_{\mathrm{H} 2 \mathrm{O}}$ for variations in major elements, $D_{\mathrm{H} 2 \mathrm{O}}$ is also dependent on the concentration of the $\mathrm{H}_{2} \mathrm{O}$ dissolved in the melt, being a factor of 5 lower in melt containing $4 \mathrm{wt} . \% \mathrm{H}_{2} \mathrm{O}$ vs. a completely dry melt (Fig. 7 inset). By combining the logarithmic regression and the relation between $\mathrm{NBO} / \mathrm{T}$ and $D_{\mathrm{H} 2 \mathrm{O}}$, we calculate $D_{\mathrm{H} 2 \mathrm{O}}$ as a function of distance from the bubble:

$D_{\mathrm{H}_{2} \mathrm{O}}=C_{\mathrm{H}_{2} \mathrm{O}} \exp \left(-8.56-\frac{19110}{T}\right) \cdot(0.057 \ln (X)+0.0732)$

where $D_{\mathrm{H} 2 \mathrm{O}}$ is in $\mathrm{m}^{2} / \mathrm{s}, C_{\mathrm{H} 2 \mathrm{O}}$ is wt.\% $\mathrm{H}_{2} \mathrm{O}, T$ is in $\mathrm{K}$, and $X$ is the distance in $\mu \mathrm{m}$ from the bubble. We incorporate these compositional and temperature dependences in the decompression model, by allowing for a spatiotemporally variable $D_{\mathrm{H} 2 \mathrm{O}}$. The parameterization we developed here leads to diffusivities that are within the $+/-0.2 \log$ unit uncertainty of the viscosity-based model of Persikov et al. (2010). This is no surprise, as their model in the region of interest is also highly constrained by the same experimental diffusivities we use here (Behrens et al., 2004; and Zhang et al., 2007), and melt viscosity is highly related to NBO/T.

Because the diffusion of $\mathrm{CO}_{2}$ in silicate melt has been shown to be relatively independent of speciation and anhydrous melt composition (Nowak et al., 2004), $\mathrm{CO}_{2}$ diffusion is less complicated than $\mathrm{H}_{2} \mathrm{O}$ diffusion. The diffusivity is well characterized for Fuego melts with a pressure- and $\mathrm{H}_{2} \mathrm{O}$-dependent Arrhenius equation (Fig. 7; Zhang et al., 2007):

$D_{\mathrm{CO}_{2}}=\exp \left(-13.99-\frac{17367+1944.8 P}{T}+\frac{(855.2+271.2 P)}{T} C_{\mathrm{H}_{2} \mathrm{O}}\right)$

where $D_{\mathrm{CO} 2}$ is in $\mathrm{m}^{2} / \mathrm{s}$ and $P$ is in GPa.

In comparison, sulfur diffusivity $\left(D_{\mathrm{S}}\right)$ in silicate melts is poorly understood not only because of the limited number of studies, but 


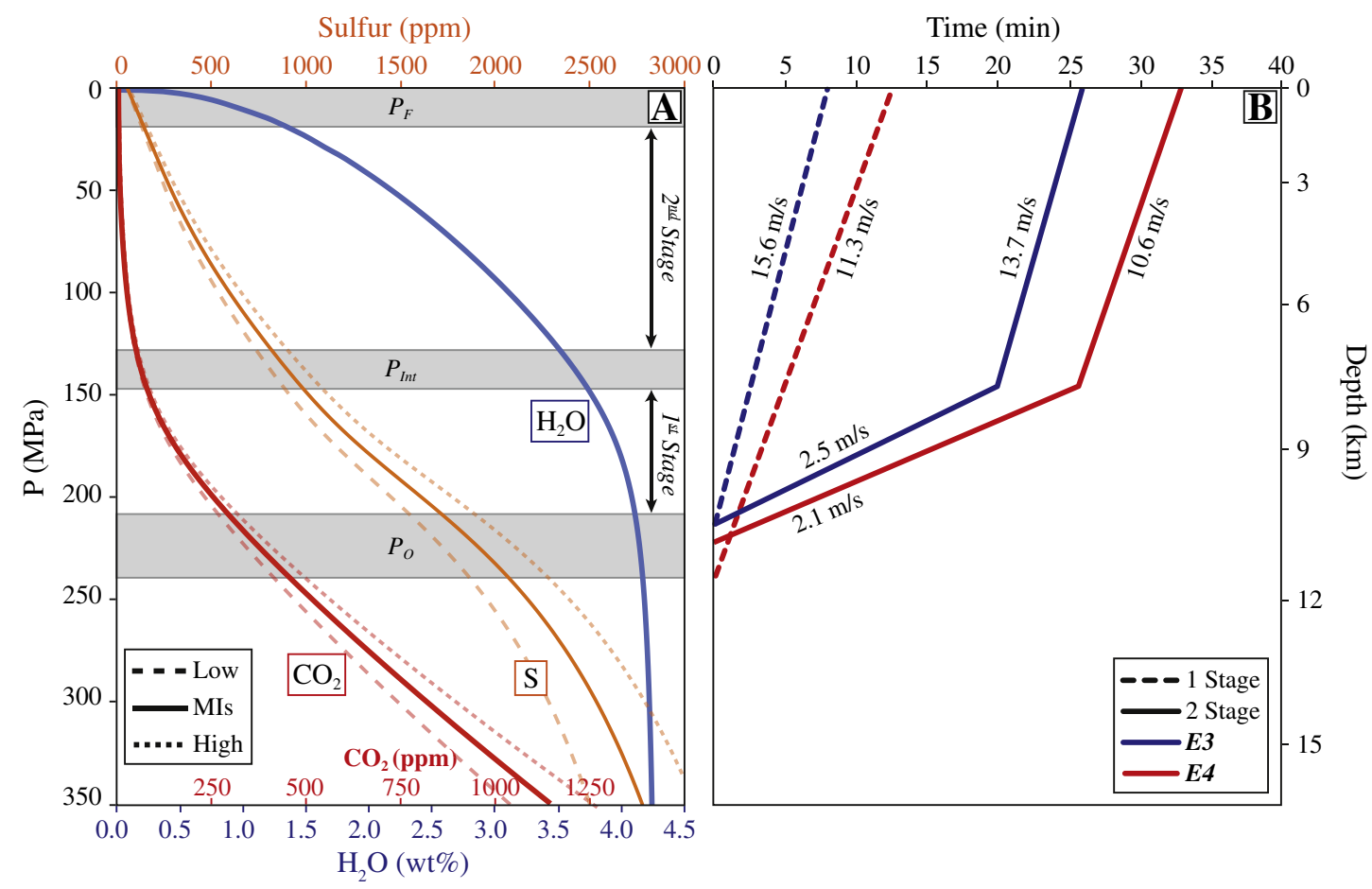

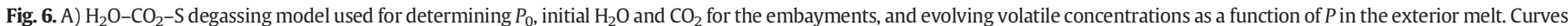

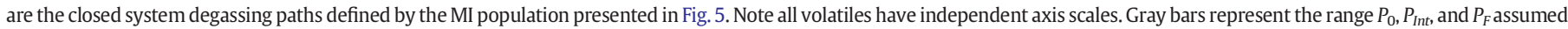

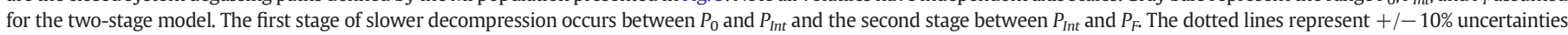

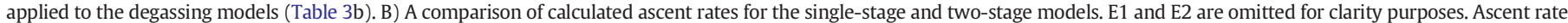

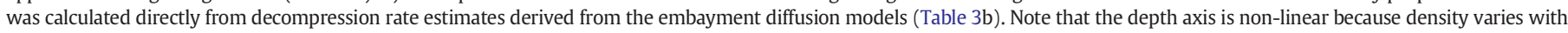

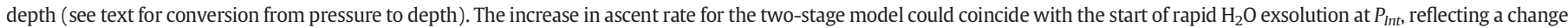
in velocity as the bubble fraction in the magma increases.

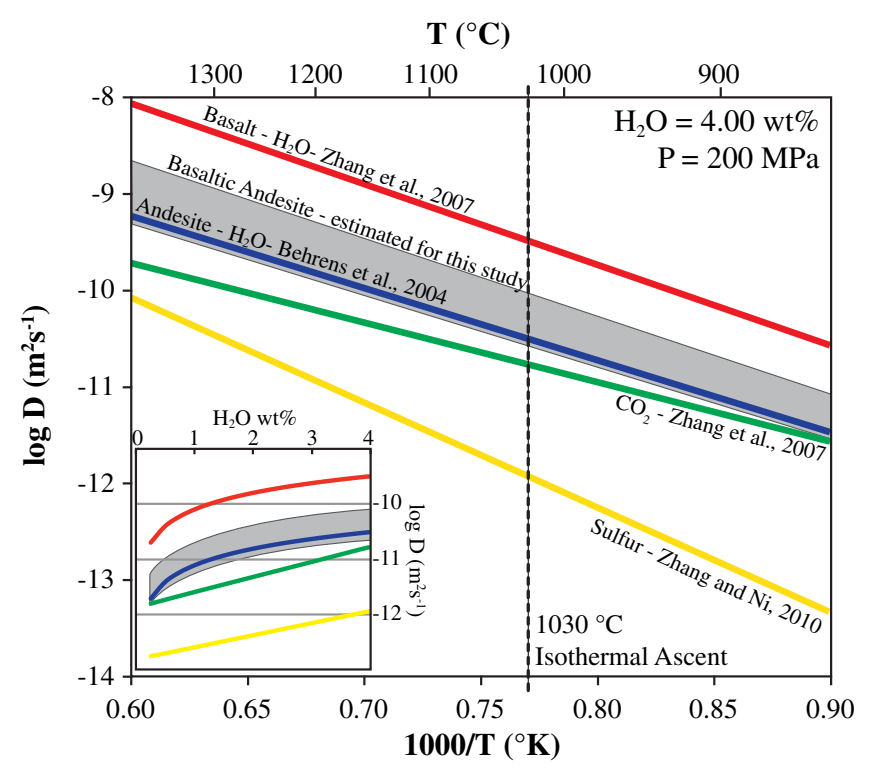

Fig. 7. Arrhenius plot illustrating $D_{\mathrm{H} 2 \mathrm{O}}, D_{\mathrm{CO} 2}$, and $D_{\mathrm{S}}$ in melt with 4 wt.\% $\mathrm{H}_{2} \mathrm{O}$ at a pressure of $200 \mathrm{MPa}$ (similar to the initial conditions for the Fuego embayments). $D_{\mathrm{H} 2 \mathrm{O}}$ is known to be highly dependent on major element melt composition. Because Fuego melt compositions fall between basalt and andesite, $D_{\mathrm{H} 2 \mathrm{O}}$ was interpolated from those compositions (see Fig. 8). The inset shows the effect of decreasing dissolved $\mathrm{H}_{2} \mathrm{O}$ on $D_{\mathrm{H} 2 \mathrm{O}}, D_{\mathrm{CO} 2}$, and $D_{S}$ at a temperature of $1030{ }^{\circ} \mathrm{C}$ and $200 \mathrm{MPa}$ (with the same color code and model as referenced). Both the major-element composition of the melt and the concentration of dissolved $\mathrm{H}_{2} \mathrm{O}$ have an order of magnitude effect on $D_{\mathrm{H} 2 \mathrm{O}}$ and both are taken into account in the diffusion modeling. (For interpretation of the references to color in this figure legend, the reader is referred to the web version of this article.) also because of the possible variation in diffusivity of different $\mathrm{S}$ species as a function of $\mathrm{fO}_{2}$ (Zhang et al., 2010). Nonetheless, existing experiments show no strong $\mathrm{fO}_{2}$ dependence, perhaps due to the predominance of melt viscosity over speciation on S diffusivity (Behrens and Stelling, 2011). We use an Arrhenius equation derived from experiments conducted on Etna and Stromboli basalts for temperature, pressure, and $\mathrm{H}_{2} \mathrm{O}$ concentrations that are relevant to the Fuego magma (Fig. 7, Zhang et al., 2007):

$D_{S}=\exp \left(-8.21-\frac{27692-651.6 C_{\mathrm{H}_{2} \mathrm{O}}}{T}\right)$

where $D_{\mathrm{S}}$ is in $\mathrm{m}^{2} / \mathrm{s}$. In these experiments the oxygen fugacity was $3 \log$ units below QFM and sulfur was present primarily as sulfide. Though rare sulfide blebs have been observed as inclusions in phenocrysts associated with this eruption, the $\mathrm{fO}_{2}$ in this experiment is much lower than the estimated oxygen fugacity in the Fuego magma $\left(\mathrm{fO}_{2} \sim \mathrm{QFM}+1\right.$; Lloyd et al., 2013). With a lack of experiments on more oxidized systems, and with the limited effects that have been observed thus far as a function of $\mathrm{fO}_{2}$, we use this sulfide-dominant Arrhenius equation.

\subsection{Single-stage decompression}

We first consider whether the simplest case, a single-stage, constant decompression rate can produce appropriate profiles for all three volatile species, given the diffusivity models and initial condition constraints outlined above. In this single-stage decompression scenario, it was assumed that each phenocryst host had fully formed an embayment and was residing at $P_{0}$. As outlined above, the maximum $S$ concentration of the inner, flat portion of each embayment was used to define 


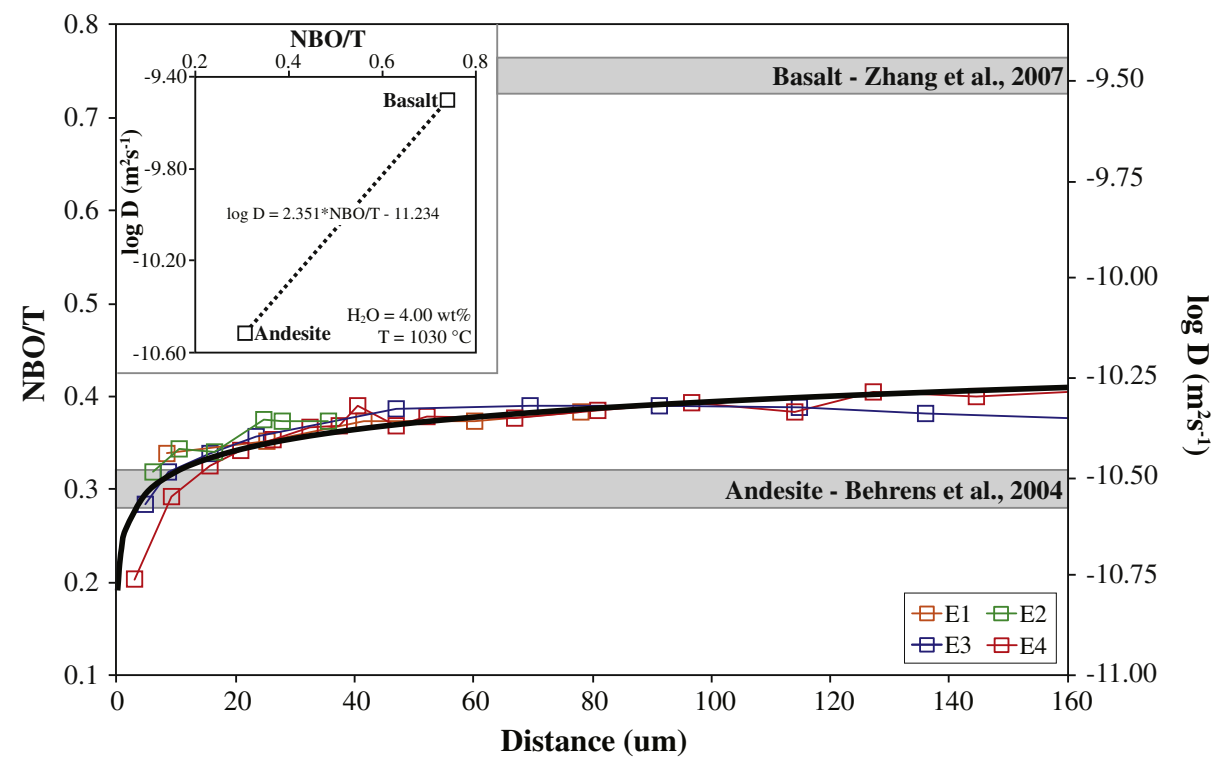

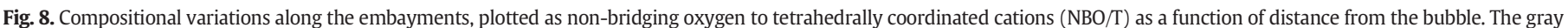

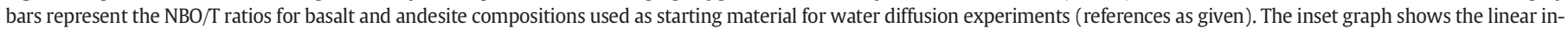

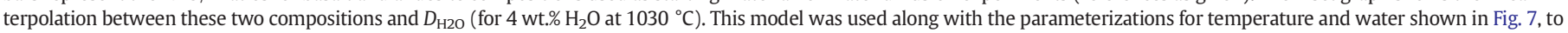
calculate $D_{\mathrm{H} 2 \mathrm{O}}$ in Fuego embayments with distance from the bubble (Eq. (4)).

the values for $P_{0}$, initial $\mathrm{H}_{2} \mathrm{O}$, and initial $\mathrm{CO}_{2}$ derived from the multielement degassing model in Fig. 6 . Then the system was decompressed at a constant rate until $P_{f}$ was reached, driving the exterior melt to degas (again, following Fig. 6), and causing the volatiles within the embayment to diffuse to the boundary, where concentrations are lower. The only free variable used to fit the diffusion profiles was the decompression rate.
We first modeled $\mathrm{H}_{2} \mathrm{O}$, because it has a well-characterized diffusivity and a nearly constant initial value ( $\sim .2$ wt.\%). The fits to $\mathrm{H}_{2} \mathrm{O}$ using this single-stage model are excellent (Fig. 9A) and yield a narrow range of decompression rates for all embayments, from 0.32 to $0.47 \mathrm{MPa} / \mathrm{s}$, for total ascent times ranging from $\sim 8$ to $\sim 12 \mathrm{~min}$ from 191 to $238 \mathrm{MPa}$ (Table 3a). The best fit was determined by minimizing the root mean square (RMS) error, which were all less than 2 RSD of the maximum
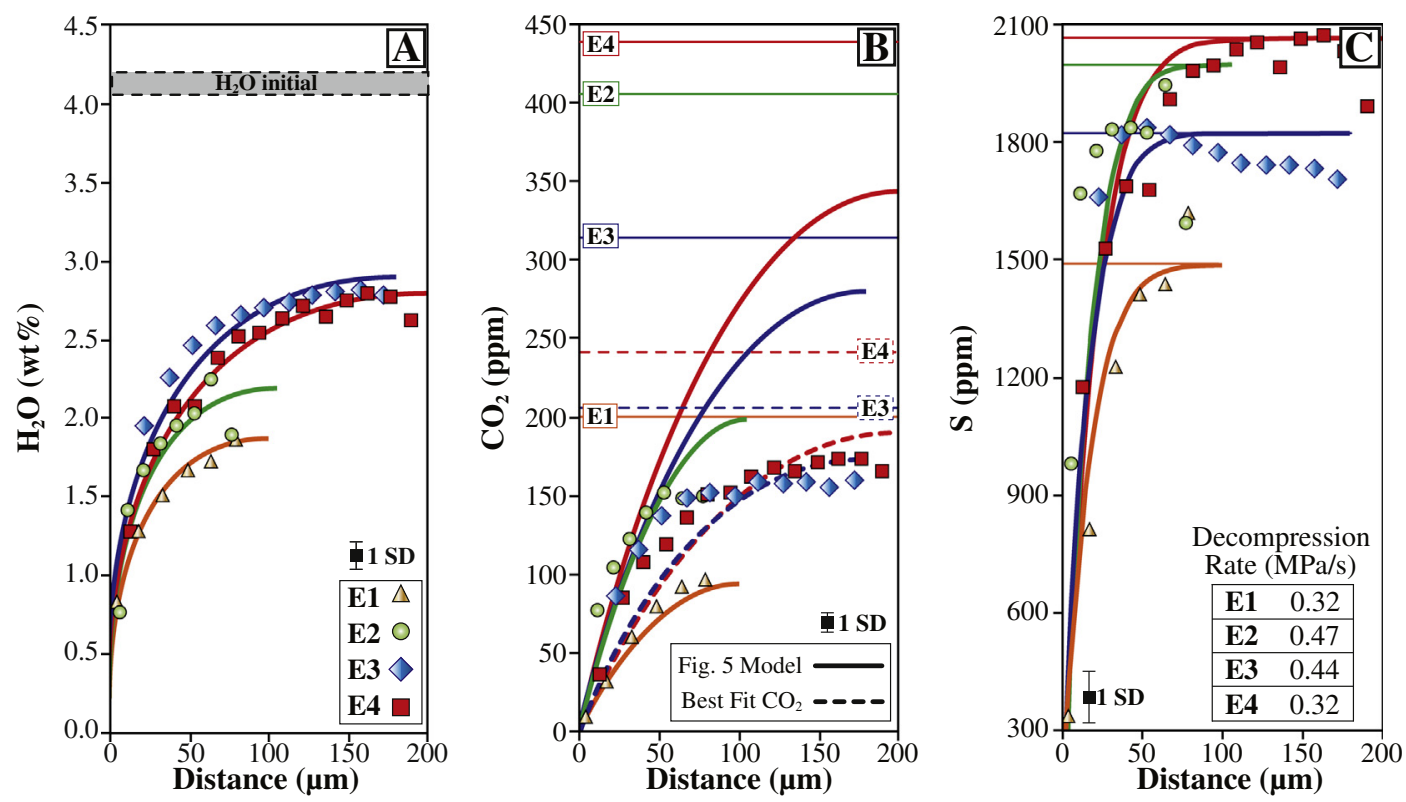

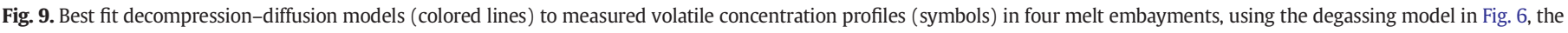

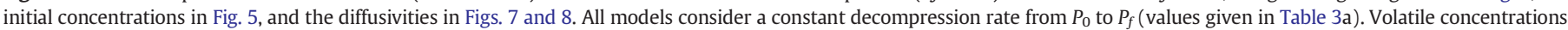

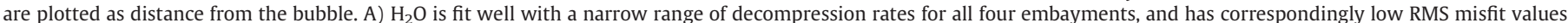

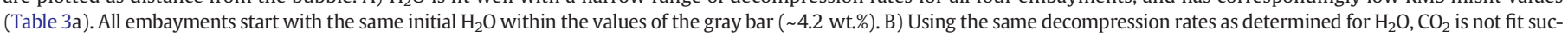

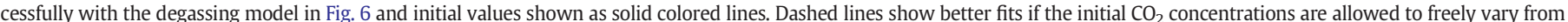

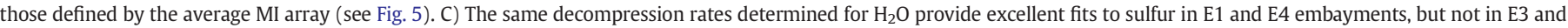

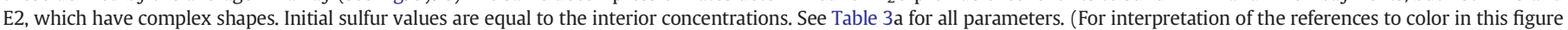
legend, the reader is referred to the web version of this article.) 
Table 3

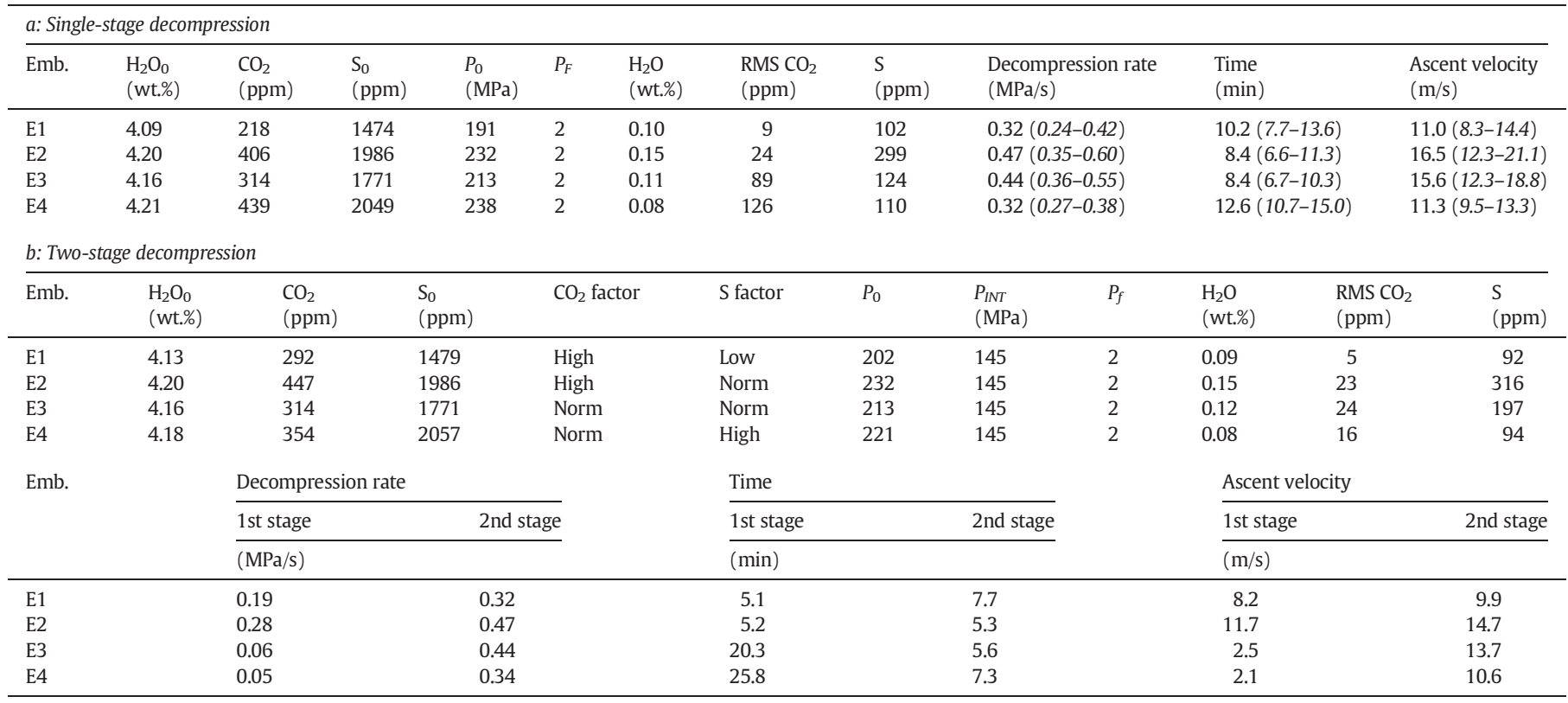

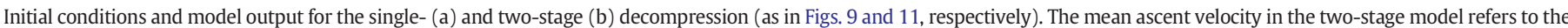

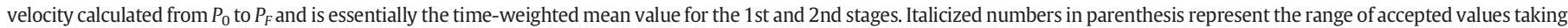

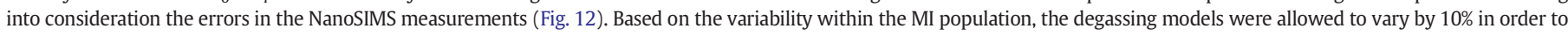

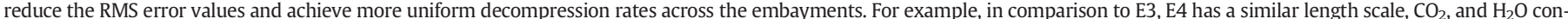

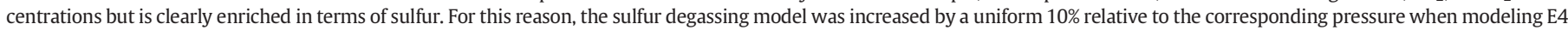
in order to compensate for this enrichment (see Fig. 6a). A 10\% enriched correction is denoted by the term "high" and a $10 \%$ depleted correction is denoted by the term "low".

measured $\mathrm{H}_{2} \mathrm{O}$ (0.18 wt.\% $\mathrm{H}_{2} \mathrm{O}$; Table 3a). The same decompression rates that fit the $\mathrm{H}_{2} \mathrm{O}$ profiles also provide adequate fits for sulfur (Fig. 9C), although the shapes of the profiles do not match the curvature of the concentration profiles in all cases (E2 and E3). Indeed, the increase in $\mathrm{S}$ toward the bubble in embayment $\mathrm{E} 3$ can only be modeled with uphill diffusion or some more complex change in the diffusivity or solubility. Given these uncertainties in sulfur behavior, and the likely changes in fluid-melt partitioning (Fiege et al., 2014) or speciation (Kelley and Cottrell, 2012) that could affect diffusion during degassing, we consider these fits successful in matching both $\mathrm{H}_{2} \mathrm{O}$ and $\mathrm{S}$ profiles with the same decompression rate. This is especially notable given the greater than two orders of magnitude difference in their diffusivities.

On the other hand, we were not able to fit the $\mathrm{CO}_{2}$ profiles for all the embayments, using the initial values predicted from the $\mathrm{S}-\mathrm{CO}_{2}$ solubility relationship in Fig. 5. The fits to the two shorter embayments (E1 and E2) were satisfactory, but the innermost $\mathrm{CO}_{2}$ concentrations predicted for the two longer embayments were greatly in excess of the measured values (i.e., $250-350$ vs. $\sim 150 \mathrm{ppm}$ ). Given the intermediate diffusivity for $\mathrm{CO}_{2}$, the short time constrained by the $\mathrm{H}_{2} \mathrm{O}$ profiles ( $10 \mathrm{~min}$ ), and the high initial concentrations (i.e., $300-450 \mathrm{ppm} \mathrm{CO}_{2}$ ), there is not enough time for the re-equilibration of $\mathrm{CO}_{2}$ in the long embayments (E3 and E4). Thus, the only solution to match the $\mathrm{CO}_{2}$ profiles given a constant decompression rate model is to impose lower initial $\mathrm{CO}_{2}$ concentrations of 200-250 ppm. This combination of high S (1800-2000 ppm) and low $\mathrm{CO}_{2}(<250 \mathrm{ppm})$ concentrations is not a common occurrence in the Fuego MI population, although it has been observed in some experimental studies (Lesne et al., 2011). On the other hand, syneruptive processes such as $\mathrm{CO}_{2}$ gas fluxing (Blundy et al., 2010), non-equilibrium $\mathrm{CO}_{2}$ degassing during rapid ascent (Pichavant et al., 2013), or nonequilibrium sulfur degassing (Fiege et al., 2014) can be invoked to explain the deviations from a closed-system degassing path. Therefore, we cannot exclude the possibility that these embayments started with lower $\mathrm{CO}_{2}$ than typical of the MI S- $\mathrm{CO}_{2}$ array. If that were the case, then all three volatiles and four embayments can be modeled with a constant decompression rate of $\sim 0.4 \mathrm{MPa} / \mathrm{s}$ and total ascent time from $\sim 9$ to $12 \mathrm{~km}$ depth in less than $12 \mathrm{~min}$.

\subsection{Two-stage decompression}

Given the difficulty in fitting the $\mathrm{CO}_{2}$ concentrations with a singlestage model, we considered the possibility that the embayments ascended in two stages, with an initial slow decompression (first stage) and a relatively faster decompression as the magma nears the surface (second stage). In this scenario, the intermediate pressure at which the magma transitions from a slower to faster decompression rate, $P_{I n t}$, has to be chosen. This proposed second stage presumably coincides with the onset of $\mathrm{H}_{2} \mathrm{O}$ degassing. This is a feature of any closed-system degassing path, where $\mathrm{CO}_{2}$ is almost entirely lost before major $\mathrm{H}_{2} \mathrm{O}$ degassing begins (Figs. 5, 6). Thus the two volatile species are sensitive to different parts of the system, and the two-stage model exploits this feature to better constrain how the decompression rate may vary with depth.

Because we have no physical constraint on $P_{\text {Int }}$, we first explored its possible range using a single embayment, E4. Although E4 is an embayment extracted from the interior of a slowly cooled bomb, which may have experienced additional time at high temperature during posteruptive delayed cooling (Lloyd et al., 2013), it displays the most systematic profiles in $\mathrm{H}_{2} \mathrm{O}, \mathrm{CO}_{2}$, and $\mathrm{S}$. We obtained $P_{0}$ using the S-based method outlined above, and then allowed $P_{I n t}$ and the decompression rate to vary independently. Our first observation was that the second stage decompression rate $(0.32 \mathrm{MPa} / \mathrm{s})$ is well-constrained by $\mathrm{H}_{2} \mathrm{O}$ and remains constant for all $P_{\text {Int }}$ values (Fig. 10C). This implies that the majority of $\mathrm{H}_{2} \mathrm{O}$ re-equilibration is occurring at shallow depths (after $P_{\text {Int }}$ ), which is consistent with the fact that $\mathrm{H}_{2} \mathrm{O}$ does not degas significantly until $<150 \mathrm{MPa}$ (Fig. 6). On the other hand, there is no unique solution for the first, deep stage because $P_{\text {Int }}$ and $\mathrm{d} P / \mathrm{d} t$ trade-off to permit similar timescales for $\mathrm{CO}_{2}$ re-equilibration (Fig. 10C). There is an upper limit to 

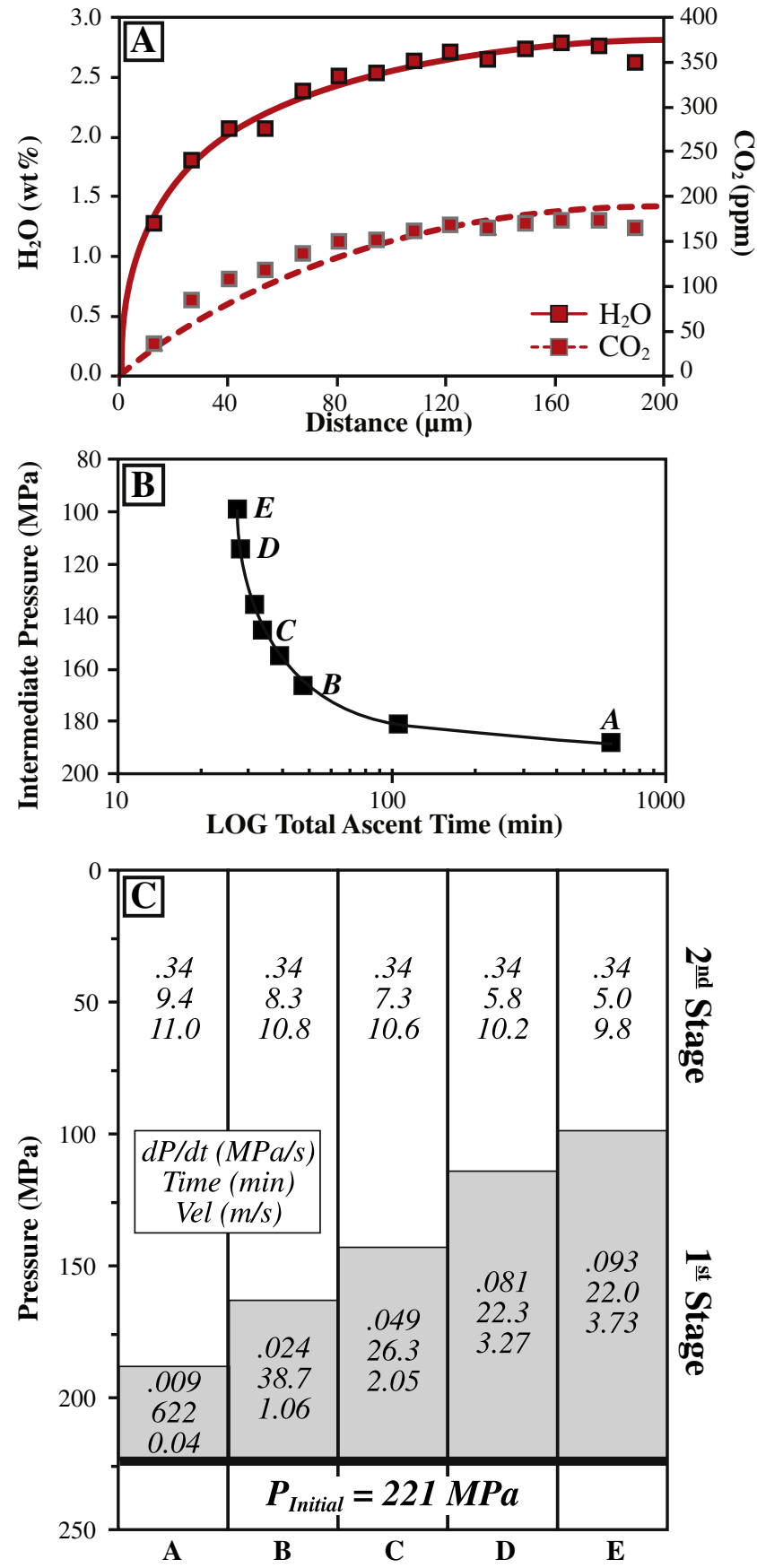

Fig. 10. Trade-off between $P_{\text {int }}$ and decompression rate in a two-stage model (i.e., $P_{0}-P_{\text {int }}$ is the first stage, and $P_{\text {int }}-P_{f}$ is the second). A) Decompression-diffusion model (colored lines) fits to $\mathrm{E} 4$ embayment $\mathrm{H}_{2} \mathrm{O}$ and $\mathrm{CO}_{2}$ data (colored symbols) for the 5 two-stage scenarios presented in panels B and C (RMS errors in Table $3 \mathrm{~b}$ ). B) $P_{\text {Int }}$ vs. the total ascent time predicted by the two-stage model. As $P_{\text {Int }}$ decreases, the total ascent time also decreases. The two-stage model can no longer produce the diffusion curves in panel $A$ at $P_{\text {Int }}>185 \mathrm{MPa}$ (scenario A) or $P_{\text {Int }}<100 \mathrm{MPa}$ (scenario E), for reasons outlined in the text. C) Parameters for the five scenarios that produce the fit observed in panel A. The first stage is largely controlled by the shape of the $\mathrm{CO}_{2}$ profile. As $P_{\text {int }}$ decreases $\left(\mathrm{CO}_{2}\right.$ concentration drops in the exterior), the decompression rate in the first stage increases (to prevent too much loss of $\mathrm{CO}_{2}$ ). The decompression rate in the second stage is largely controlled by the $\mathrm{H}_{2} \mathrm{O}$ profile, which is unaffected by the ascent history at $P_{\text {int }}>145 \mathrm{MPa}$ (see Fig. 6). (For interpretation of the references to color in this figure legend, the reader is referred to the web version of this article.)

$P_{\text {Int }}$ at around $185 \mathrm{MPa}$, where the dissolved $\mathrm{CO}_{2}$ concentration in the decompressing magma is $\sim 250 \mathrm{ppm}$ (Fig. 6), which is too high to create a flat plateau in the inner embayment of $\sim 175$ ppm (Fig. 10A). For this reason we consider $185 \mathrm{MPa}$ to be the maximum $P_{\text {Int }}$, and the corresponding total ascent time of $\sim 10 \mathrm{~h}$ to be the maximum for the twostage scenario. At the other limit, as $P_{I n t}$ shallows, an increase in decompression rate is needed to compensate for the increasing concentration gradient between $\mathrm{CO}_{2}$ in the embayment and in the exterior melt. At pressures less than $140 \mathrm{MPa}$, the dissolved $\mathrm{CO}_{2}$ in the decompressing magma approaches concentrations less than $65 \mathrm{ppm}$, and embayment re-equilibration is relatively insensitive to further decreases in $\mathrm{CO}_{2}$ solubility. This asymptotic limit at lower $P_{\text {Int }}$ (Fig. 10B) results in a minimum total ascent time of $\sim 30 \mathrm{~min}$.

Although this experiment with E4 demonstrates how a range of $P_{\text {Int }}$ results in good fits, we modeled the other embayments using a constant value for $P_{\text {Int }}$ of $145 \mathrm{MPa}$ (Table 3b). This value is guided by both observed MI entrapment pressures and what might plausibly control $P_{\text {Int }}$ dynamically. The Fuego MIs were likely trapped by a slow crystal growth mechanism as they do not exhibit the textural characteristics of fast dendritic growth (Faure and Schiano, 2005). If we interpret this slow crystal growth to occur prior to or during the first, slow stage of decompression, then the MI with the shallowest entrapment pressure would represent the transition to the second, faster stage of decompression. In this case, the MI with the lowest $S$ (our proxy for $P_{0}$ in this study) corresponds to an entrapment pressure of $145 \mathrm{MPa}$ (calculating solubility pressure from $\mathrm{H}_{2} \mathrm{O}$ and $\mathrm{CO}_{2}$ and VolatileCalc, Newman and Lowenstern, 2002; see also Fig. 5). This pressure also coincides physically with where the decompressing magma starts to lose significant $\mathrm{H}_{2} \mathrm{O}$, which being the major volatile species, will dominate the buoyancy and thus ascent of the system (Mastin and Ghiorso, 2000). Thus, given that there is a clear change at $\sim 145 \mathrm{MPa}$ both in the melt inclusion population, and in the predicted mass fraction of vapor in the system, we use this value of $P_{\text {Int }}$ for the remaining embayment calculations.

The results of fitting all the embayments with two stages of decompression are shown in Fig. 11. Unsurprisingly, the decompression rate for the second, shallow stage of ascent is identical to that what was calculated for the single-stage model (Table $3 \mathrm{~b}$ ), because both are dominated by $\mathrm{H}_{2} \mathrm{O}$-loss. The decompression rate for the first, deep stage of ascent is then constrained by $\mathrm{CO}_{2}$. With additional time to reequilibrate, higher initial $\mathrm{CO}_{2}$ concentrations are permitted, which is more consistent with the $\mathrm{H}_{2} \mathrm{O}-\mathrm{CO}_{2}-\mathrm{S}$ degassing model defined by the MIs (Fig. 5). As a result of the slower initial ascent, there is also a noticeable decrease in the RMS error for $\mathrm{S}$ in the two embayments exhibiting systematic S profiles (110 to $94 \mathrm{ppm}$ for E4 and 102 to $92 \mathrm{ppm}$ for E1). This improvement in fit is a result of the additional time at increased concentrations of $S$ and aids in recreating the inflection of the measured $S$ concentrations between a distance of 40 and $70 \mu \mathrm{m}$ from the bubble (Fig. 11C). In the case of the two longer embayments that were not fit well by the single-stage scenario (E3 and E4), decompression rates for the initial stage of ascent are an order of magnitude slower $(\sim 0.05 \mathrm{MPa} / \mathrm{s})$ than those calculated for the second, more rapid stage of ascent $(\sim 0.4 \mathrm{MPa} / \mathrm{s})$. This has the effect of increasing the total ascent time by 15 to $20 \mathrm{~min}$ (Table 3 ). Although the two shorter embayments (E1 and E2) were fit relatively well with the single-stage scenario, increasing the total ascent times by $\sim 3 \mathrm{~min}$ further improves the fits.

In summary, a constant decompression rate scenario predicts rates between 0.3 and $0.5 \mathrm{MPa} / \mathrm{s}$ and total ascent times between 8 and $12 \mathrm{~min}$, but requires some ad hoc adjustments to the initial $\mathrm{CO}_{2}$ concentrations of the different embayments. If decompression is split into a slower and faster regime, with the transition occurring around $150 \mathrm{MPa}$, total ascent times between 10 and 35 min produce higher quality fits to the data, with a single $\mathrm{H}_{2} \mathrm{O}-\mathrm{CO}_{2}-\mathrm{S}$ degassing model. Because the first stage of the two-stage scenario cannot be solved uniquely (Fig. 10), we cannot exclude the possibility that there is a slower decompression event at depth that could take up to $10 \mathrm{~h}$. However, at pressures below $150 \mathrm{MPa}$, the decompression rate is well-determined and fast (0.3-0.5 MPa/s and 8-12 min in duration) and may be more relevant to the dynamics of the eruption. 

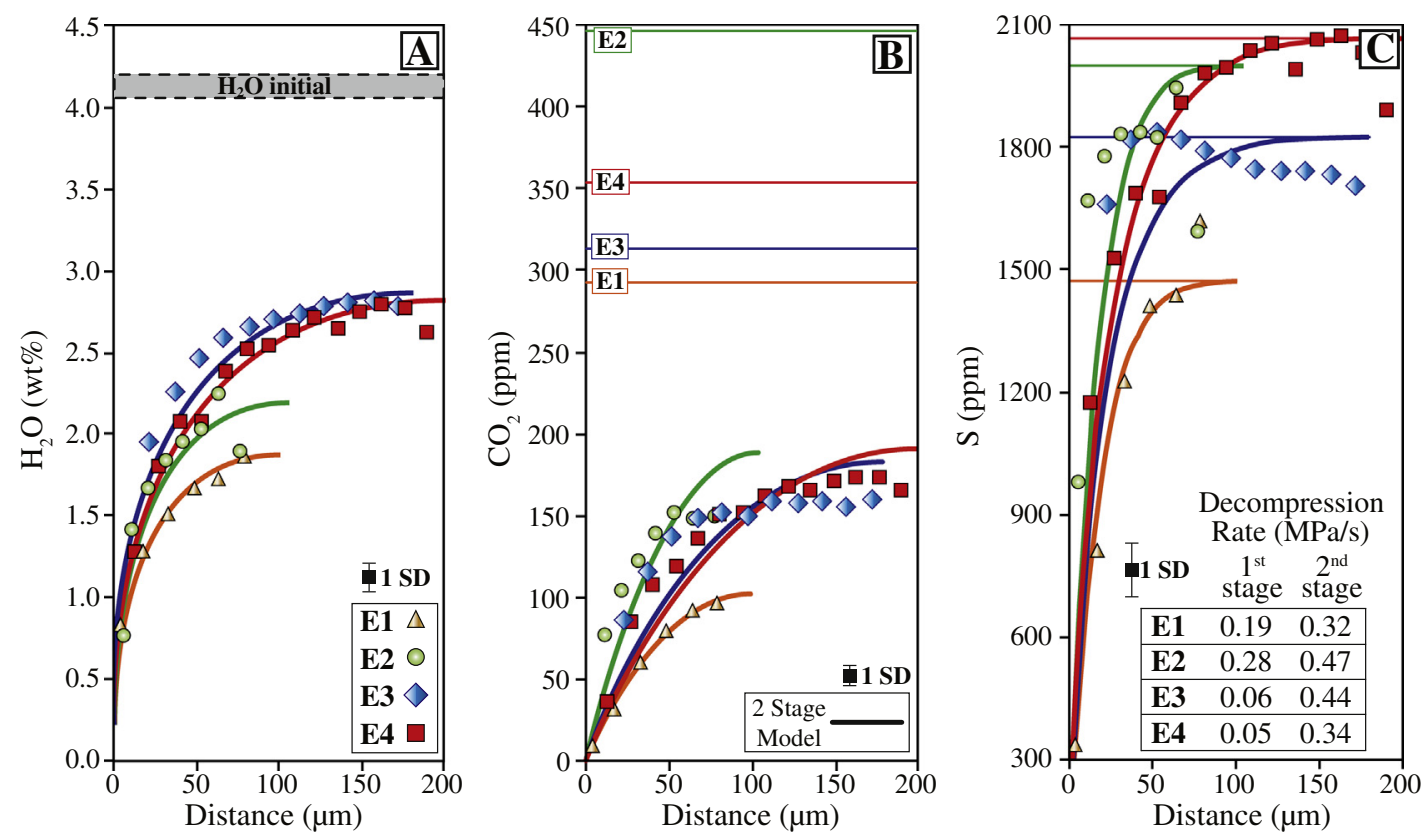

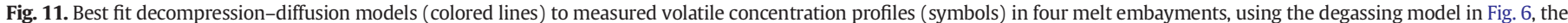

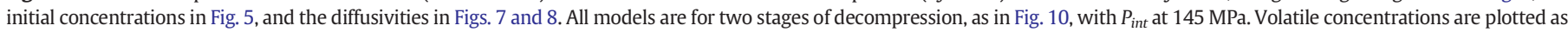

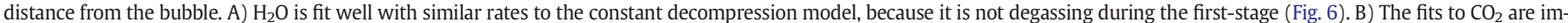

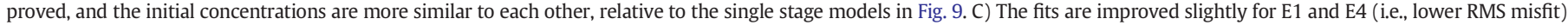

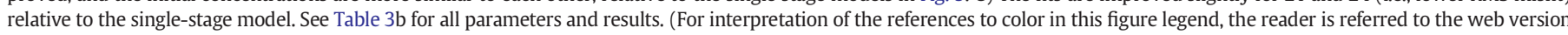
of this article.)

\subsection{Calculating depth and ascent rate}

We use the method outlined in Humphreys et al. (2008) to convert decompression rate to ascent velocity, which uses a magma density model that incorporates the effects of bubble exsolution and $40 \%$ preexisting phenocrysts in the magma column (Wilson et al., 1980):

$\rho=\left[\left(\frac{1-n}{\rho_{m}}\right)+\left(\frac{n R T}{P}\right)\right]^{-1}$

where $\rho_{m}$ is the bubble-free, hydrous magma density $\left(2450 \mathrm{~kg} / \mathrm{m}^{3}\right), n$ is the mass fraction of exsolved volatiles ( $7 \%$ at $P_{0}$ and $60 \%$ at $P_{F}$ based on output from SolEx; Witham et al., 2012), $R$ is the gas constant and $P$ is the pressure. Density was calculated by averaging the embayment compositions from Table 1 and assuming $4.20 \mathrm{wt} . \% \mathrm{H}_{2} \mathrm{O}$ (major-element volume and thermal expansion data from Lange and Carmichael (1987) and $\mathrm{H}_{2} \mathrm{O}$ from Ochs and Lange (1999)). The ascent velocity $(v)$ is then calculated from:

$v=\frac{1}{t}\left(\frac{P_{i}}{\rho_{i} g}-\frac{P_{f}}{\rho_{f} g}\right)$

where $g$ is the gravitational acceleration $\left(9.81 \mathrm{~m} / \mathrm{s}^{2}\right)$ and $t$ is the duration of the model. Ascent velocities range from 11.0 to $16.5 \mathrm{~m} / \mathrm{s}$ in the case of constant decompression (Table 3a) and 2.1 to $11.7 \mathrm{~m} / \mathrm{s}$ and 9.9 to $14.7 \mathrm{~m} / \mathrm{s}$ for the first and second stages respectively (Table $3 \mathrm{~b}$ ). If the volcanic conduit was assumed to be lithostatic (assuming a crustal density of $2700 \mathrm{~kg} / \mathrm{m}^{3}$ ), the calculated ascent velocities would decrease by $<2 \mathrm{~m} / \mathrm{s}$.

\subsection{Effect of differential clast cooling}

In our previous study (Lloyd et al., 2013), we demonstrated that MIs from bomb-sized clasts lost $\mathrm{H}_{2} \mathrm{O}$ in comparison to MIs from ash and lapilli. A conductively cooled $6-\mathrm{cm}$ volcanic bomb will remain at high temperatures and open to diffusion for an additional 5-10 min after eruption. The observed diffusive re-equilibration in the bomb MIs could occur in this timeframe only for the fastest laboratory measurements of $D_{\mathrm{H} 2 \mathrm{O}}$ in olivine. For more representative $D_{\mathrm{H} 2 \mathrm{O}}$, the bomb MI would require additional time at high temperature, perhaps in the upper conduit during post-fragmentation comminution or as a result of slower ascent (Lloyd et al., 2013). E4 is an embayment from a volcanic bomb, and both single- and two-stage decompression models predicted longer equilibration times than the embayments in the ash and lapilli samples (i.e., a difference of $\sim 5 \mathrm{~min}$ for the single-stage model and $\sim 20 \mathrm{~min}$ in the two-stage scenario). Although some of this additional time results from the higher $P_{0}$ predicted for the bomb embayment (due to its higher initial sulfur), the rest could derive from conductive cooling post-eruption.

It may also be significant that the two embayments from ash-sized clasts (E2 and E3) yield the highest ascent velocities and shortest rise times for both models (Table 3). Lloyd et al. (2013) had speculated that ash-sized fragments might preferentially form from portions of magma that ascend more rapidly, due to contrasts in bubble number density, crystallinity or other aspects of their physical properties. More rapid ascent rates for the ash-hosted embayments are also suggested from their sulfur profiles. If the interior of all the embayments is unaffected by diffusion of sulfur, then the length scale of the outer gradient should scale with the diffusive timescale. Combined NanoSIMS and EMP profiles (Supplementary Table 2) show that such outer sulfur boundary layers are shortest $(25-30 \mu \mathrm{m})$ for ash-hosted embayments, longer for the lapilli-hosted embayment $(40-50 \mu \mathrm{m})$, and longest for the bomb-hosted embayment $(75 \mu \mathrm{m})$. While this is consistent with faster decompression for the ash-hosted embayments, the length scales of the sulfur profiles are too short to be consistent with the decompression rates calculated from the $\mathrm{H}_{2} \mathrm{O}$ profiles. This is apparent in Fig. 11, where the diffusion profiles derived from $\mathrm{H}_{2} \mathrm{O}$ provide poor fits to $\mathrm{S}$ profiles in embayments E2 and E3. It is also noteworthy that S does not vary monotonically in these embayments, but undergoes an increase toward the outlet before sharply declining. Thus, the shape and length of the outer sulfur boundary layer in E2 and E3 may reflect enrichment from the thinning embayment neck or other processes than diffusive loss 
during ascent, such as non-equilibrium effects related to changing sulfate solubility as a function of pressure (Fiege et al., 2014). Thus, although there may be some different processes and rates accompanying the embayments from different clasts, the results from the four embayments are remarkably similar. A larger number of embayments from a greater variety of clast sizes would be necessary to isolate those effects due to variable cooling and ascent rates as a function of clast size.

\subsection{Implications for the 1974 Fuego eruption}

The decompression rates determined here are the first for the 1974 eruption of Fuego, but they can be compared to previous magma supply rate estimates. Based on the volume flux of erupted material, Rose et al. (2008) estimated a magma eruption rate of $3.2 \times 10^{6} \mathrm{~kg} / \mathrm{s}$ for the October 14 phase of the eruption. Because the October 17 phase was observed to be $30 \%$ larger than the initial phase, we consider a magma supply rate of $10^{6} \mathrm{~kg} / \mathrm{s}$ to be a minimum for this day of the eruption. A simple mass balance calculation can relate ascent rate to mass eruption rate for an assumed conduit dimension (Rutherford, 2008):

$M=\pi r^{2} \rho_{F} v$

where $M$ is the mass eruption rate $(\mathrm{kg} / \mathrm{s}), r$ is the conduit radius, $\rho_{F}$ is the dense rock equivalent density of the Fuego magma $\left(2750 \mathrm{~kg} / \mathrm{m}^{3}\right.$, Rose et al., 2008), and $v$ is the velocity ( $\mathrm{m} / \mathrm{s})$. More recent explosive eruptions at Fuego (May 1999 and September 2012) have created crater radii on the order of 40 to $65 \mathrm{~m}$, which could be connected to a conduit with an order of magnitude smaller radius (Escobar, pers. comm., 2013). Given a range of mass eruption rates between $3 \times 10^{6}$ and $6 \times 10^{6} \mathrm{~kg} / \mathrm{s}$ and a reasonable range of conduit radius, the corresponding range of ascent rates calculated by mass balance is 14 to $28 \mathrm{~m} / \mathrm{s}$ for a $5 \mathrm{~m}$ conduit and 3.5 to $6.9 \mathrm{~m} / \mathrm{s}$ for a $10 \mathrm{~m}$ conduit radius, which are comparable with the range of ascent rates calculated for this study (Table 3). Cashman (2004) also identified a range of decompression rates for sub-Plinian eruptions between 0.01 and $1 \mathrm{MPa} / \mathrm{s}$, which also are consistent with the calculations from this study ( $\sim 0.3$ to $0.5 \mathrm{MPa} / \mathrm{s}$ in the upper $\sim 7 \mathrm{~km}$ ).

Following the development in Qin et al. (1992), several recent studies have used fully-enclosed, olivine-hosted melt inclusions to constrain magma ascent based on the diffusive equilibration of $\mathrm{H}_{2} \mathrm{O}$ through olivine (Chen et al., 2013; Lloyd et al., 2013). $\mathrm{H}_{2} \mathrm{O}$ diffusion in olivine has larger uncertainties than that in melt. Experimental determinations of $\mathrm{H}^{+}$diffusion coefficients in olivine span at least three orders of magnitude (Farver, 2010), due to multiple proposed mechanisms that may dominate under different $\mathrm{fO}_{2}$ and $\mathrm{fH}_{2} \mathrm{O}$ regimes (Kohlstedt and Mackwell, 1998). For the October $17 \mathrm{MIs}$, estimates for ascent span more than an order of magnitude based on the assumed diffusion mechanism in olivine (Lloyd et al., 2013), from $<12 \mathrm{~m} / \mathrm{s}$ if the fast redox mechanism dominates (Kohlstedt and Mackwell, 1998) and $<0.5 \mathrm{~m} / \mathrm{s}$ if the slow metal vacancy mechanism dominates (Demouchy and Mackwell, 2006). Taken at face value, the results from the fast redox mechanism are more compatible with the embayment results determined here. It is worth noting that $\mathrm{H}^{+}$diffusion by the redox mechanism in olivine is on the same order of magnitude as $\mathrm{H}_{2} \mathrm{O}$ diffusion in andesitic melt, which raises the question whether any $\mathrm{H}_{2} \mathrm{O}$-loss occurred through the olivine instead of exclusively through the melt in the embayment. However, diffusive equilibration through the olivine is also a function of its partition coefficient (Qin et al., 1992), which is very low in olivine $\left(\mathrm{Kd}_{\mathrm{H} 2 \mathrm{O}}^{\text {ol } / \mathrm{O}}=0.001\right.$; Aubaud et al., 2004; Koga et al., 2003), and so equilibration will be much more efficient through the melt embayment to the bubble. Moreover, significant diffusive equilibration ( $>10 \%$ ) was only observed for relatively small melt inclusions in the Fuego samples ( $<30 \mu \mathrm{m}$ radius; Lloyd et al., 2013); the larger relative volume of the melt embayments (equivalent to a 100-200 $\mu \mathrm{m}$ diameter inclusion) would only experience $1-2 \%$ equilibration through the olivine over 10-30 min, based on the calculations in Lloyd et al. (2013, their Fig. 11).
A recent study has revealed a bimodal distribution of bubble sizes in eruptive products from the October 14 eruptive phase of 1974 Fuego eruption (Genareau et al., 2013). Bimodal distributions of bubble sizes and variations in the complexity of bubble shape have generally been thought to represent separate nucleation events during explosive eruptions (Blower et al., 2002). In the case of the October 14 phase, it was observed that the distribution of bubbles could be separated into two modes: one mode that was characterized by large but relatively rare bubbles and a second mode with small but very numerous bubbles. These two bubble modes have been interpreted to represent two vesiculation events that occur at a relatively greater depth (large mode) followed by a second event (small mode) at a later stage of ascent (Genareau et al., 2013). Without pressure estimates for this transition in nucleation style, we cannot thoroughly apply this to our model; however, these observations do lend support to multiple stages of decompression during magma ascent.

The 1974 eruption has been described as sub-Plinian with characteristics similar to some vulcanian eruptions (Rose et al., 1978). The 10-day eruption was characterized by explosions with a one-minute periodicity during each of the four main phases. All the samples studied here were collected on the same day and reflect volcanic material erupted in a 48-hour period; however, it is unlikely that all of these samples were erupted during the same explosion. Because there is a natural variability in the degree of explosivity during a given phase of the eruption, it is not likely that the decompression rate was constant over the course of the eruption, or even a single day. Based on this evidence, it should not be an expectation that all four embayments exhibit uniform decompression rates. Nonetheless, the relatively uniform decompression rates calculated (0.3-0.5 MPa/s in the upper $\sim 7 \mathrm{~km}$ of the conduit) suggest that the embayment-hosting clasts experienced similar conditions during that phase of the eruption.

\subsection{Comparison to previous embayment studies}

Here we consider how our results compare to ascent rates calculated from previous embayment studies. For simplicity, we focus on the results of the single-stage model, which is well determined from $\mathrm{H}_{2} \mathrm{O}$ and agrees with the faster stage of the two-stage model. The range of decompression rates calculated for the four embayments (0.32-0.47 MPa/s) represents the best fits, but here we also take into account the error associated with the NanoSIMS measurements. If we calculate best fit decompression rates for each embayment (Fig. 12), taking the minimum RMS \pm 0.08 wt.\% ( $1 \mathrm{SD}$ at the maximum $\mathrm{H}_{2} \mathrm{O}$ of 2.8 wt.\% measured in the embayments), we find a range for all embayments of $0.24-0.60 \mathrm{MPa} / \mathrm{s}$ or $\sim 8-21 \mathrm{~m} / \mathrm{s}$ (Table $3 \mathrm{a}$ ).

The embayment re-equilibration technique has been previously applied to two other explosive eruptions. Liu et al. (2007) measured concentration gradients in quartz-hosted melt pockets from the $26.5 \mathrm{ka}$ Oruanui eruption of Taupo volcano, New Zealand and found that the results were best fit by a decompression rate of $0.001-$ $0.007 \mathrm{MPa} / \mathrm{s}(0.04-0.35 \mathrm{~m} / \mathrm{s})$. The Oruanui eruption produced about $530 \mathrm{~km}^{3}$ of moderate- to high-silica rhyolite magma (Wilson, 2001), which was relatively volatile rich $\left(\mathrm{H}_{2} \mathrm{O}=5.00 \mathrm{wt} . \%, \mathrm{CO}_{2}=300 \mathrm{ppm}\right)$. It is considered to be the largest volcanic eruption in the last $70 \mathrm{k}$ years and was estimated to have had a volcanic explosivity index (VEI) of 8. In comparison to the decompression rates calculated for Fuego (Fig. 12), Oruanui is more than two orders of magnitude slower for an eruption that produced more than 5000 times the dense rock equivalent of the entire 1974 eruption of Fuego $\left(>0.1 \mathrm{~km}^{3}\right.$, Rose et al., 1978). This calculation has been previously noted to be unusually slow for what is predicted from theoretical models (Papale et al., 1998; Rutherford, 2008), possibly a result of the large FTIR beam size that did not sample the minimum concentrations near the embayment outlet. This is an unexpected disparity because magma ascent rate has been suggested to scale with explosivity (Cashman, 2004); however, the eruptive complexities 


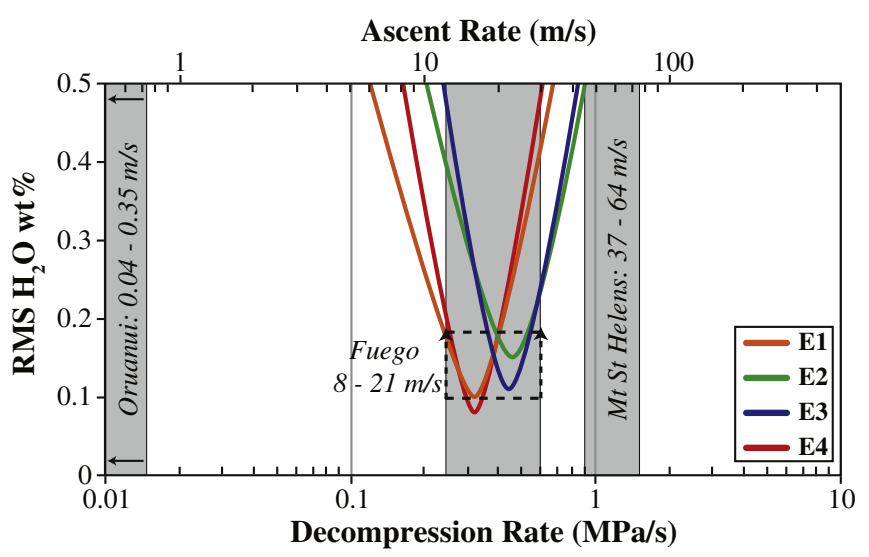

Fig. 12. Single-stage decompression rate results for Fuego embayments relative to previous embayment studies (Oruanui - Liu et al., 2007; Mt St Helens - Humphreys et al., 2008). Fuego embayment solutions are plotted against the RMS misfit for the model. The dashed box represents $2 \mathrm{RSD}$ from an RMS value of $0.1 \mathrm{wt} . \% \mathrm{H}_{2} \mathrm{O}$. This results in a range of decompression rates from 0.24 to $0.60 \mathrm{MPa} / \mathrm{s}$ (equivalent to $8-21 \mathrm{~m} / \mathrm{s}$ ) that satisfy the conditions for all four embayments. This exercise demonstrates that the solutions calculated for Fuego are unique relative to the two previous studies. Ascent rate on the top axis is applicable to the Fuego system only, and calculated using Eq. (5) in the text (Humphreys et al., 2008). For the other studies, gray bars represent the range of calculated decompression rates only.

associated with a catastrophic, caldera collapse may prevent a simple comparison with a standard sub-Plinian arc volcano such as Fuego.

Humphreys et al. (2008) analyzed plagioclase-hosted embayments and estimated a decompression rate for the plinian phase of the $1980 \mathrm{Mt}$. St. Helens (MSH) eruption ranging from 0.9 to $1.6 \mathrm{MPa} / \mathrm{s}$ (37-64 m/s), about half an order of magnitude faster than what we report for Fuego (Fig. 12). With a mass eruption rate about 1 order of magnitude greater than the October 14 phase of the Fuego eruption $\left(1.44 \times 10^{7} \mathrm{~kg} / \mathrm{s}\right)$, it appears that this is a case where magma ascent rate does scale with explosivity. However, there are a few differences in the methods and assumptions that preclude a direct comparison between the Fuego and MSH embayments. As was shown earlier, $\mathrm{H}_{2} \mathrm{O}$ concentration profiles are most useful when analyzing the later stages of ascent (Fig. 6). Without the constraints from $\mathrm{CO}_{2}, \mathrm{~S}$ and majorelement measurements, the initial conditions and the earliest stages of decompression at MSH are relatively less understood, potentially resulting in faster timescales. Additionally, it was assumed that the MSH magmatic system underwent an instantaneous pressure decrease from $P_{0}$ to $P_{F}$ (230-30 MPa). For Fuego, the decompression model was systematically stepped through a closed-system degassing path, which we assumed was more appropriate for this sub-Plinian eruption. This results in a smaller concentration gradient throughout the majority of the diffusion model for Fuego, resulting in longer time scales.

The MSH and Fuego embayments also differ in terms of the lowest measured $\mathrm{H}_{2} \mathrm{O}$ concentrations. Whereas we measure concentrations as low as $0.76 \mathrm{wt} . \%$ in the embayments (Table 2) and $0.04 \mathrm{wt} . \%$ in the matrix glass, Humphreys et al. assumed $\mathrm{H}_{2} \mathrm{O}_{\mathrm{F}}$ concentrations between 1.0 and 2.0 wt.\%, which minimizes the pressure drop and effectively reduces the overall time required for re-equilibration. The elevated $\mathrm{H}_{2} \mathrm{O}$ concentrations at the outlet for the MSH embayments and in the matrix glass were interpreted as evidence for disequilibrium degassing. Given the potential for supersaturation of $\mathrm{H}_{2} \mathrm{O}$ in rhyolitic systems at decompression rates $>0.25 \mathrm{MPa} / \mathrm{s}$ (Gardner et al., 1999), Humphreys et al. suggested that the reported decompression rates were potentially overestimated as a result of assuming equilibrium degassing. The fast decompression rates estimated for the Fuego embayments introduce the possibility of disequilibrium degassing for the Fuego magmatic system as well. Given the greater $\mathrm{D}_{\mathrm{H} 2 \mathrm{O}}$ in mafic melt and the similarity of the lowest measured concentrations of $\mathrm{H}_{2} \mathrm{O}$ in the embayments with the measured groundmass concentrations (Fig. 3), the extent of supersaturation and disequilibrium degassing of $\mathrm{H}_{2} \mathrm{O}$ during decompression may be limited in the Fuego magmatic system. Although $\mathrm{H}_{2} \mathrm{O}$ may be undergoing equilibrium degassing, $\mathrm{CO}_{2}$-over-saturated basaltic melts have been generated experimentally for ascent rates greater than $\sim 1.5 \mathrm{~m} / \mathrm{s}$ (Pichavant et al., 2013). However, Fuego MIs show no obvious signs of disequilibrium degassing, which would manifest as $\mathrm{CO}_{2}$ in excess of closed system degassing. Instead, closed-system degassing is an adequate model for $\mathrm{H}_{2} \mathrm{O}-\mathrm{CO}_{2}$ and $\mathrm{S}$ (Fig. 5), and the inferred vapor/ liquid partition coefficients for $\mathrm{S}$ are consistent with equilibrium values (Fiege et al., 2014) at an $\mathrm{fO}_{2}$ near QFM +1 (as for Fuego, Lloyd et al., 2013). Because $S$ has a lower diffusivity than $\mathrm{CO}_{2}$, we likewise expect $\mathrm{CO}_{2}$ to reflect near equilibrium degassing at Fuego. Finally, the success in fitting both $\mathrm{H}_{2} \mathrm{O}$ and $\mathrm{S}$ diffusion profiles with the same decompression rate supports the equilibrium degassing model we use.

Direct comparison of embayment-derived ascent velocities for the different eruptions (e.g., Oranui, Mt St Helens and Fuego) is complicated by the different magma viscosities and degassing styles. Future research in diffusion chronometry, especially on similar volcanic systems that exhibit varying explosive styles, is necessary to reveal further insights into magma ascent during explosive volcanism.

\section{Conclusions}

We have analyzed four olivine-hosted embayments erupted on October 17, 1974 at Volcán de Fuego for the purpose of assessing magma ascent velocities during explosive basaltic eruptions. Utilizing a NanoSIMS to measure multi-volatile profiles, we observed that $\mathrm{H}_{2} \mathrm{O}$, $\mathrm{CO}_{2}$, and $\mathrm{S}$ decrease in concentration toward outlet bubbles, consistent with decreasing diffusive loss. $\mathrm{Cl}$ and $\mathrm{F}$ vary little in concentration throughout the embayment, consistent with their lack of degassing over most of the ascent path. We also observe sharp gradients in majorelement concentrations in the outer $20-40 \mu \mathrm{m}$ of the embayment that could be produced by crystallization at the bubble/melt boundary. Because $D_{\mathrm{H} 2 \mathrm{O}}$ is compositionally dependent, a parameterization was designed specifically to account for the effects of this chemical boundary layer on diffusivities. We defined the initial and external melt conditions for the decompression model based on the closed-system degassing path defined by the MI population. A numerical diffusion model is used to fit the compositional profiles along the embayments, with continuously varying diffusivities and external melt compositions as a function of pressure. The primary control on the length scale and shape of the concentration profiles is the decompression rate.

We present two scenarios for the decompression of the Fuego magma prior to eruption. One scenario assumes a constant decompression rate throughout ascent. In this case, the free variables are constrained in the following order: $P_{0}$ is established by the inferred initial sulfur that is allowed to vary between the four embayments; $P_{F}$ is set by an extrapolation from the measurements closest to the bubble and is constant for all embayments; and $\mathrm{d} P / \mathrm{d} t$ was found for each embayment by fitting to the measured $\mathrm{H}_{2} \mathrm{O}$ profile. This method resulted in decompression rates ranging from 0.32 to $0.47 \mathrm{MPa} / \mathrm{s}(11.0-16.5 \mathrm{~m} / \mathrm{s})$, which notably also fit the sulfur profiles, except for those without monotonic shapes. The $\mathrm{CO}_{2}$ profiles could only be fit in the constant decompression models by adjusting the initial $\mathrm{CO}_{2}$ concentrations independently of the other volatiles. Better fits were also obtained for $\mathrm{CO}_{2}$ using a two-stage model: an initial slow stage followed by a faster second stage. Decompression rates calculated with this method ranged from 0.05 to $0.28 \mathrm{MPa} / \mathrm{s}$ and 0.32 to $0.47 \mathrm{MPa} / \mathrm{s}$ for the first and second stages respectively, and may record the acceleration of the magma during ascent. The slower, first stage is not well constrained, and could occur over minutes to hours. The second stage rates are very similar to the constant decompression model, as both are primarily sensitive to $\mathrm{H}_{2} \mathrm{O}$ degassing at pressures lower than $145 \mathrm{MPa}$.

For this reason we define the minimum and maximum decompression rates calculated for this eruption based on the constant decompression results, which range from 0.24 to $0.60 \mathrm{MPa} / \mathrm{s}(\sim 8-21 \mathrm{~m} / \mathrm{s})$ for all four embayments when taking into account analytical uncertainties. 
Within the context of the October 17 eruption at Fuego, the ascent rates calculated in this study compare favorably to estimates based on mass eruption rate and prior MI re-equilibration timescales. The calculated decompression rates also fall within a fairly limited range that is consistent with the explosivity of this sub-Plinian eruption. These results should encourage the further use of embayments to constrain magma ascent dynamics for a wider range of magma types and eruptive styles.

\section{Acknowledgments}

This research was supported by the National Science Foundation: grants EAR-09-48533 and EAR-11-45177 to ASL and TP, grant EAR-1250414 to PR, and grant EAR-09-48478 to EHH. WR acknowledges NSF support for work on Fuego and nearby volcanoes since 1972, the most recent being PIRE-05-30109. We appreciate the technical support of Jianhua Wang at CIW and Juliane Gross at the AMNH during the electron microprobe data collection. Constructive reviews from Madeleine Humphreys, Yang Liu, and Jim Webster improved the clarity of our arguments and data presentation. Finally, we would like to acknowledge the editorial work of Malcolm J. Rutherford and the staff associated with the Journal of Volcanology and Geothermal Research.

\section{Appendix A. Supplementary data}

Supplementary data to this article can be found online at http://dx. doi.org/10.1016/j.jvolgeores.2014.06.002.

\section{References}

Anderson Jr., A.T., 1991. Hourglass inclusions: theory and application to the Bishop Rhyolitic Tuff. Am. Mineral. 76, 530-547.

Aubaud, C., Hauri, E.H., Hirschmann, M.M., 2004. Hydrogen partition coefficients between nominally anhydrous minerals and basaltic melts. Geophys. Res. Lett. 31, L20611

Baker, D.R., Freda, C., Brooker, R.A., Scarlato, P., 2005. Volatile diffusion in silicate melts and its effects on melt inclusions. Ann. Geophys. 48, 699-717.

Behrens, H., Stelling, J., 2011. Diffusion and redox reactions of sulfur in silicate melts. Rev. Mineral. Geochem. 73, 79-111.

Behrens, H., Zhang, Y., Xu, Z., 2004. $\mathrm{H}_{2} \mathrm{O}$ diffusion in dacitic and andesitic melts. Geochim. Cosmochim. Acta 68, 5139-5150.

Berlo, K., Stix, J., Roggensack, K., Ghaleb, B., 2012. A tale of two magmas, Fuego Guatemala. Bull. Volcanol. 74, 377-390.

Blower, J.D., Keating, J.P., Mader, H.M., Phillips, B., 2002. The evolution of bubble size distributions in volcanic eruptions. J. Volcanol. Geotherm. Res. 120, 1-23.

Blundy, J.D., Cashman, K.V., Rust, A.C., Witham, F., 2010. A case for $\mathrm{CO}_{2}$-rich arc magmas. Earth Planet. Sci. Lett. 290, 289-301.

Carr, M.J., Walker, J.A., 1987. Intra-eruption changes in composition of some mafic to intermediate tephras in Central-America. J. Volcanol. Geotherm. Res. 33, 147-159.

Cashman, K.V., 2004. Volatile controls on magma ascent and degassing. AGU Monogr. 150, $109-124$

Cashman, K.V., Sparks, R.S.J., 2013. How volcanoes work: a 25 year perspective. Geol. Soc Am. Bull. 125, 664-690.

Castro, J.M., Dingwell, D.B., 2009. Rapid ascent of rhyolitic magma at Chaitén volcano, Chile. Nature 461, 780-783.

Chen, Y., Provost, A., Schiano, P., Cluzel, N., 2013. Magma ascent rate and initial water concentration inferred from diffusive water loss from olivine-hosted melt inclusions. Contrib. Mineral. Petrol. 165, 525-541.

Costa, F., Morgan, D., 2010. Time constraints from chemical equilibration in magmatic crystals. In: Dosseto, A., Turner, S., Van Orman, J.A. (Eds.), Timescales of Magmatic Processes: From Core to Atmosphere. Wiley-Blackwell, pp. 125-159.

Demouchy, S., Mackwell, S.J., 2006. Mechanisms of hydrogen incorporation and diffusion in iron-bearing olivine. Phys. Chem. Miner. 33, 347-355.

Demouchy, S., Jacobsen, S.D., Gaillard, F., Stern, C.R., 2006. Rapid magma ascent recorded by water diffusion profiles in mantle olivine. Geology 34, 429-432.

Endo, E.T., Murray, T.L., Power, J.A., 1996. A comparison of pre-eruption, real-time seismic amplitude measurements for eruptions at Mount St. Helens, Redoubt Volcano, Mount Spurr, and Mount Pinatubo. In: Newhall, C.G., Punongbayan, R.S. (Eds.), Fire \& Mud: Eruptions and Lahars of Mount Pinatubo, Philippines. University of Washington Press, pp. 233-246.

Farver, J.R., 2010. Oxygen and hydrogen diffusion in minerals. Rev. Mineral. Geochem. 72, 447-507.

Faure, F., Schiano, P., 2005. Experimental investigation of equilibration conditions during forsterite growth and melt inclusion formation. Earth Planet. Sci. Lett. 236, 882-898.

Fiege, A., Behrens, H., Holtz, F., Adams, F., 2014. Kinetic vs. thermodynamic control of degassing of $\mathrm{H}_{2} \mathrm{O}-\mathrm{S}+\mathrm{Cl}$-bearing andesitic melts. Geochim. Cosmochim. Acta 125 241-264.
Gardner, J.E., Hilton, M., Carroll, M.R., 1999. Experimental constraints on degassing of magma: isothermal bubble growth during continuous decompression from high pressure. Earth Planet. Sci. Lett. 168, 201-218.

Genareau, M.J., Mulukutlu, G.K., Proussevitch, A.A., Durant, A.J., Rose, W.I., Sahagian, D.L., 2013. The size range of bubbles that produce ash during explosive volcanic eruptions. J. Appl. Volcanol. 2, 4. http://dx.doi.org/10.1186/2191-5040-2-4.

Geschwind, C.H., Rutherford, M.J., 1995. Crystallization of microlites during magma ascent: the fluid mechanics of 1980-86 eruptions at Mount St. Helens. Bull. Volcanol. 57, 356-370.

Gonnermann, H.M., Manga, M., 2007. The fluid mechanics of volcanic eruptions. Annu. Rev. Fluid Mech. 39, 321-356.

Gudmundsson, M.T., Thordarson, T., Höskuldsson, A., Larsen, G., Björnsson, H., Prata, F.J., Oddsson, B., Magnússon, E., Högnadóttir, T., Petersen, G.N., Hayward, C.L., Stevenson, J.A., Jónsdóttir, I., 2012. Ash generation and distribution from the April-May 2010 eruption of Eyjafjallajokull, Iceland. Sci. Rep. 2, 572. http://dx.doi.org/10.1038/srep00572.

Hauri, E.H., Shaw, A.M., Wang, J., Dixon, J.E., King, P.L., Mandeville, C., 2006. Matrix effects in hydrogen isotope analysis of silicate glasses by SIMS. Chem. Geol. 235, 352-365.

Hauri, E.H., Weinreich, T., Saal, A.E., Rutherford, M.C., Van Orman, J.A., 2011. High preeruptive water contents preserved in lunar melt inclusions. Science 333, 213-215.

Humphreys, M.C.S., Menand, T., Blundy, J.D., Klimm, K., 2008. Magma ascent rates in explosive eruptions: constraints from $\mathrm{H}_{2} \mathrm{O}$ diffusion in melt inclusions. Earth Planet. Sci. Lett. 270, 25-40.

Kelley, K.A., Cottrell, E., 2012. The influence of magmatic differentiation on the oxidation state of Fe in a basaltic arc magma. Earth Planet. Sci. Lett. 329-330, 109-121.

Koga, K., Hauri, E.H., Hirschmann, M., Bell, D., 2003. Hydrogen concentration analyses using SIMS and FTIR: comparison and calibration for nominally anhydrous minerals. Geochem. Geophys. Geosyst. 4. http://dx.doi.org/10.1029/2002GC000378.

Kohlstedt, D.L., Mackwell, S.J., 1998. Diffusion of hydrogen and intrinsic point defects in olivine. Z. Phys. Chem. 207, 147-162.

Lange, R.A., Carmichael, I.S.E., 1987. Densities of $\mathrm{Na}_{2} \mathrm{O}-\mathrm{K}_{2} \mathrm{O}-\mathrm{CaO}-\mathrm{MgO}-\mathrm{FeO}-\mathrm{Fe}_{2} \mathrm{O}_{3}-$ $\mathrm{Al}_{2} \mathrm{O}_{3}-\mathrm{TiO}_{2}-\mathrm{SiO}_{2}$ liquids: new measurements and derived partial molar properties. Geochim. Cosmochim. Acta 51, 2931-2946.

Lesne, P., Kohn, S., Blundy, J., Witham, F., Botcharnikov, R., Behrens, H., 2011. Experimental simulation of closed-system degassing in the system basalt $-\mathrm{H}_{2} \mathrm{O}-\mathrm{CO}_{2}-\mathrm{S}-\mathrm{Cl}$. J. Petrol. $52,1737-1762$.

Liu, Y., Anderson, AT, Wilson, C.JN , 2007. Melt pockets in phenocrysts and decompression rates of silicic magmas before fragmentation. J. Geophys. Res. 112, B06204. http://dx.doi.org/10.1029/2006JB004500.

Lloyd, A.S., Plank, T., Ruprecht, P., Hauri, E.H., Rose, W., 2013. Volatile loss from melt inclusions in pyroclasts of differing sizes. Contrib. Mineral. Petrol. 165, 129-153.

Mastin, L.G., Ghiorso, M.S., 2000. A numerical program for steady-state flow of magmagas mixtures through vertical eruptive conduits. U.S. Geol. Surv. Open-File Rep. 00-209.

Metrich, N., Wallace, P.J., 2008. Volatile abundances in basaltic magmas and their degassing paths tracked by melt inclusions. Rev. Mineral. Geochem. 69, 273-331.

Mysen, B.O., Richet, P., 2005. Silicate Glasses and Melts: Properties and Structure. Elsevier Science.

Newman, S., Lowenstern, J.B., 2002. Volatile-calc: a silicate melt- $\mathrm{H}_{2} \mathrm{O}-\mathrm{CO}_{2}$ solution model written in Visual Basic for Excel. Comput. Geosci. 28, 597-604.

$\mathrm{Ni}, \mathrm{H}$., Xu, Z., Zhang, Y., 2013. Hydroxyl and molecular $\mathrm{H}_{2} \mathrm{O}$ diffusivity in haploandesitic melt. Geochim. Cosmochim. Acta 103, 36-48.

Nowak, M., Schreen, D., Spickenbom, K., 2004. Argon and $\mathrm{CO}_{2}$ on the race track in silicate melts: a tool for the development of a $\mathrm{CO}_{2}$ speciation and diffusion model. Geochim. Cosmochim. Acta 68, 5127-5138.

Ochs, F.A., Lange, R.A., 1999. The density of hydrous magmatic liquids. Science 283, 314-317.

Okumura, S., Nakashima, S., 2006. Water diffusion in basaltic to dacitic glasses. Chem. Geol. 227, 70-82

Papale, P., Neri, A., Macedonio, G., 1998. The role of magma composition and water content in explosive eruptions, 1. Conduit ascent dynamics. J. Volcanol. Geotherm. Res. 87, 75-93.

Persikov, E.S., Newman, S., Bukhtiyarov, P.G., Nekrasov, A.N., Stolper, E.M., 2010. Experimental study of water diffusion in haplobasaltic and haploandesitic melts. Chem. Geol. 276, 241-256.

Peslier, A.H., Luhr, J.F., 2006. Hydrogen loss from olivines in mantle xenoliths from Simcoe (USA) and Mexico: mafic alkalic magma ascent rates and water budget of the subcontinental lithosphere. Earth Planet. Sci. Lett. 242, 302-319.

Pichavant, M. Di Carlo, I., Rotolo, S.G. Scaillet, B., Burgisser, A. Le Gall, N., Martel, C., 2013. Generation of $\mathrm{CO}_{2}$ rich melts during basalt magma ascent and degassing. Contrib. Mineral. Petrol. 166, 545-561.

Proussevitch, A., Sahagian, D.L., 2005. Bubbledrive-1: a numerical model of volcanic eruption mechanisms driven by disequilibrium magma degassing. J. Volcanol. Geotherm. Res. 143, 89-111.

Qin, Z., Lu, F., Anderson, A.T., 1992. Diffusive re-equilibration of melt and fluid inclusions. Am. Mineral. 77, 565-576.

Roggensack, K., 2001. Unraveling the 1974 eruption of Fuego volcano (Guatemala) with small crystals and their young melt inclusions. Geology 29, 911-914.

Rose, W.I., Anderson, A.T., Woodruff, L.G., Bonis, S.B., 1978. October 1974 basaltic tephra from Fuego Volcano - description and history of magma body. J. Volcanol. Geotherm. Res. 4, 3-53.

Rose, W.I., Self, S., Murrow, P.J., Bonadonna, C., Durant, A.J., Ernst, G.J., 2008. Nature and significance of small volume fall deposits at composite volcanoes: insights from the October 14, 1974 Fuego eruption, Guatemala. Bull. Volcanol. 70, 1043-1067.

Ruprecht, P., Plank, T., 2013. Feeding andesitic eruptions with a high-speed connection from the mantle. Nature 500, 68-72.

Rutherford, M.J., 2008. Magma ascent rates. Rev. Mineral. Geochem. 69, 241-271. 
Rutherford, M.J., Devine, J.D., 2003. Magmatic conditions and magma ascent as indicated by hornblende phase equilibria and reactions in the 1995-2001 Soufriere Hills magma. J. Petrol. 44, 1433-1454.

Sisson, T.W., Layne, G.D., 1993. $\mathrm{H}_{2} \mathrm{O}$ in basalt and basaltic andesite glass inclusions from 4 subduction related volcanoes. Earth Planet. Sci. Lett. 117, 619-635.

Spera, F.J., 1984. Carbon dioxide in petrogenesis III: role of volatiles in the ascent of alkaline magma with special reference to xenolith-bearing magmas. Contrib. Mineral. Petrol. 88, 217-232.

Szramek, L., Gardner, J.E., Larsen, J., 2006. Degassing and microlite crystallization of basaltic andesite magma erupting at Arenal volcano, Costa Rica. J. Volcanol. Geotherm. Res. 157, 182-201.

Toramaru, A., 2006. BND (bubble number density) decompression rate meter for explosive volcanic eruptions. J. Volcanol. Geotherm. Res. 154, 303-316.

Wilson, C.J.N., 2001. The 26.5 ka Oruanui eruption, New Zealand: an introduction and overview. J. Volcanol. Geotherm. Res. 112, 133-174.
Wilson, L., Sparks, R.S.J., Walker, G.P.L., 1980. Explosive volcanic eruptions - IV. The control of magma properties and conduit geometry on eruption column behavior. Geophys. J. Int. 63, 117-148.

Witham, F., Blundy, J., Kohn, S.C., Lesne, P., Dixon, J., Churakov, S.V., Botchamikov, R., 2012 SolEx: a model for mixed COHSCl-volatile solubilities and exsolved gas compositions in basalt. Comput. Geosci. http://dx.doi.org/10.1016/j.cageo.2011.09.021.

Zhang, Y., Cherniak, D.J., 2010. Diffusion in minerals and melts: introduction. Rev. Mineral. Geochem. 72, 1-4.

Zhang, Y., Ni, H., 2010. Diffusion of H, C, and O components in silicate melts. Rev. Mineral. Geochem. 72, 171-225

Zhang, Y., Xu, Z., Zhu, M., Wang, H., 2007. Silicate melt properties and volcanic eruptions. Rev. Geophys. 45, RG4004. http://dx.doi.org/10.1029/2006RG000216.

Zhang, Y., Ni, H., Chen, Y., 2010. Diffusion data in silicate melts. Rev. Mineral. Geochem. 72, 311-408. 